\title{
JG|U
}

Gutenberg School of Management and Economics \& Research Unit "Interdisciplinary Public Policy" Discussion Paper Series

\section{Choosing Who You Are: The Structure and Behavioral Effects of}

\section{Revealed Identification Preferences}

Florian Hett, Markus Kröll, Mario Mechtel January 24,2019

Discussion paper number 1903

Johannes Gutenberg University Mainz

Gutenberg School of Management and Economics Jakob-Welder-Weg 9

55128 Mainz

Germany

https://wiwi.uni-mainz.de/ 
Florian Hett

Chair of Digital Economics

Gutenberg School of Management and Economics

Johannes Gutenberg-University Mainz

Jakob-Welder-Weg 4

55128 Mainz

Germany

forian.hett@uni-mainz.de

Markus Kröll

Department of Management and Microeconomics

Goethe University Frankfurt

Theodor-W.-Adorno-Platz

60323 Frankfurt/Main

Germany

kroell@econ.uni-frankfurt.de

Mario Mechtel

Leuphana University Lüneburg

Institute of Economics

Universitätsallee 1

21335 Lüneburg

Germany

mario.mechtel@leuphana.de 


\title{
Choosing Who You Are: The Structure and Behavioral Effects of Revealed Identification Preferences
}

\author{
Florian Hett* \\ Markus Kröll ${ }^{\dagger}$ \\ Mario Mechtel ${ }^{\ddagger}$
}

January 24,2019

\begin{abstract}
Social identity is an important driver of behavior. But where do differences in social identity come from? We use a novel laboratory experiment to measure individual identification preferences as a potential source of behavioral heterogeneity. Facing a trade-off between monetary payments and belonging to different groups, individuals are willing to forego significant earnings to avoid certain groups and thereby reveal their identification preferences. We then show that these identification preferences are systematically related to behavioral heterogeneity in groupspecific social preferences. These results illustrate the importance of identification as a choice and its relevance for explaining individual behavior.
\end{abstract}

JEL Codes: C91, C92, D03, D91

Keywords: Social Identity, Identification Preferences, Social Preferences, Outgroup Discrimination, Behavioral Heterogeneity

\footnotetext{
${ }^{*}$ Gutenberg School of Management and Economics, Johannes Gutenberg-University Mainz, Jakob-Welder-Weg 4, D-55128 Mainz, Germany, e-mail: florian.hett@uni-mainz.de.

${ }^{\dagger}$ Department of Management and Microeconomics, Goethe University Frankfurt, Theodor-W.-Adorno-Platz 4, D-60323 Frankfurt/Main, Germany, e-mail: kroell@econ.uni-frankfurt.de.

${ }^{\ddagger}$ Leuphana University Lüneburg, Institute of Economics, Universitätsallee 1, D-21335 Lüneburg, Germany, e-mail: mario.mechtel@leuphana.de.
} 


\section{Introduction}

Individuals' social identity - their sense of who they are based on their perceived membership in social groups - has substantial effects on how they act 1 $^{1}$ Accordingly, a large literature shows the distinct role social identity plays across a broad variety of domains, ranging from the optimal design of the educational system and organizations (Akerlof and Kranton 2002, 2005, Fryer and Torelli 2010), preferences for redistribution (Klor and Shayo 2010), female labor supply and the gender pay gap (Bertrand et al. 2015), dishonest behavior and crime, and even risk-taking and amplified dynamics in financial markets (Cohn et al. 2014, 2015a,b). Understanding the origins of variation in social identity would therefore facilitate understanding differences in behavior. While existing studies typically assume that an individual takes her identity as given or study its long-term determinants (Nunn 2010), the social identity approach claims that individuals also actively choose their identity through identification (Tajfel 1974). If individuals in fact do "choose who they are", differences in behavior are not only driven by exogenous variation in individuals' identity, but also endogenously affected by their choice of identity.

In this paper, we investigate how individuals want to "choose who they are" and whether differences in these identification preferences accordingly explain behavior. We consider identification to constitute a choice among different alternative social categories. For instance, an African American alumn of Stanford, born in Wisconsin, working for a bank in New York can, among others, identify with her gender, race, alma mater, origin, occupation, or current residence. From an economic perspective, treating identity as a choice implies that individuals should have preferences regarding these alternatives. To elicit these preferences, we run a laboratory experiment where participants face a tradeoff between monetary payments and joining different groups that have different characteristics. The monetary valuations for different group memberships can then be interpreted as a revealed preference ordering over different identities at the individual level.

Our first objective is assessing whether revealed identification preferences explain heterogeneity in the behavioral effects of social identity, namely outgroup discrimination. If individuals differ in their identification preferences, these differences could be a key element in explaining the considerable heterogeneity of identity-related behavior between individuals (Mueller 2017, Kranton et al. 2018, Paetzel and Sausgruber 2018). Further, this would imply that understanding and changing individual behavior originating from social identity requires insights in how individuals actually want to identify. Our second objective is therefore to isolate general factors shaping the structure of identification preferences, i.e. finding out who people "want to be".

\footnotetext{
${ }^{1}$ The feeling of belonging to a particular group leads to a stronger compliance with behavioral stereotypes (Shih et al. 1999, Benjamin et al. 2010). It segregates society by defining insiders and outsiders which serves as a basis for discrimination, for instance in distributional decisions (Chen and Li 2009, Kranton et al. 2016) or trust (Fershtman and Gneezy 2001). It also affects the effectiveness of cooperation and coordination in groups (Eckel and Grossman 2005, Chen and Chen 2011) and the extent to which norms are being enforced (Goette et al. 2006).
} 
Empirically studying identification preferences is challenging for a number of reasons. An individual's social identity is multi-dimensional: individuals can identify with many different social categories whose salience and relevance vary over time (Tajfel 1974, Akerlof and Kranton 2000). This multi-dimensionality creates substantial ambiguity with respect to what individuals perceive to be available identities in a specific situation, such that the researcher has imperfect knowledge about the individual's perceived choice set. Second, identity is a cognitive concept: it is not a part of how people act, but how people think (Tajfel 1974, Tajfel and Turner 1979). Hence, identification is an inherently cognitive action without a straight-forward behavioral - and thus observable counterpart. Third, in almost all natural settings, different identities have different "instrumental values". This means that an apparent identification preference can typically be rationalized by some sort of expected future (material) payoff (Algan et al. 2013). Think, for example, of joining a political party: While it might sound reasonable to interpret such a decision as being driven by identity considerations, it is not clear how to disentangle the identity motive from indirect material motives through improved career and network opportunities within the party. To really isolate pure identification preferences, it is crucial to provide a setting in which such strategic concerns about the instrumental value of identity are minimized $?^{2}$

Our research design features a laboratory experimental setup that explicitly addresses these challenges. For the experiment, we recruit supporters of two different German football clubs at two different universities. At the beginning, all participants have to carry out a mathematics task (adding numbers) individually before we assign them to groups. Groups differ with respect to the football club their members support and the performance (above or below median) of their members in the mathematics task. This yields four different types of groups: "good" and "bad" groups for supporters of each of the two clubs. Within these groups, participants then interact in a non-incentivized group activity (solving picture riddles). This creates a social environment with a fixed, known set of group identities.

To make identification preferences observable, we rely on the notion that joining a group and identifying with it are closely related. In the next step, we therefore confront participants with the possibility to be re-assigned to one of the other groups. Using the Becker-DeGroot-Marschak (1964) procedure, we elicit each individual's willingness to accept re-assignment to each of the alternative groups and interpret this as revealing a preference for identifying with this particular group. Importantly, our design even enables us to elicit these differences within-subject: we allow individuals to express a different willingness to accept re-assignment to different alternative groups. Finally, the high degree of anonymity combined with control over monetary payoffs eliminate any potential direct or indirect incentives for group-switching within or outside the experiment (instrumental values). In the second part of the experiment, each participant makes a series of distributional choices affecting herself as well as another individual. As these choices are made conditional on

\footnotetext{
${ }^{2}$ In a recent field experiment, Burstyzn et al. (2016) argue along similar lines in order to identify political ideology as an intrinsic motivation for political behavior.
} 
group-membership of the other player, we are able to investigate whether revealed identification preferences are related to differences in discriminatory behavior and thereby assess the behavioral relevance of identification preferences.

Our results show the relevance of deliberate self-identification in understanding identity-related behavior. First, we find that individuals generally display preferences for identification, as they are willing to sacrifice a substantial part of their experimental earnings to manipulate their membership in specific groups. In particular, the monetary amounts they are willing to forego depend on the characteristics of the group in question. This dependency is in line with the theoretical literature, where it is commonly assumed that individuals prefer to identify with groups whose stereotypes are more similar to their own characteristics (social distance) and with groups whose average salient characteristics are superior to those of comparison groups (social status) (Tajfel et al. 1971, Tajfel 1972, 1978, Tajfel and Turner 1979, Turner et al. 1987, Akerlof and Kranton 2000, Shayo 2009, Bernard et al. 2016). Our experiment is explicitly designed to allow for these two dimensions to vary across different groups and thus to analyze their role in detail: We assume that participants perceive a larger social distance to groups of supporters of the other football club and perceive groups with a better mathematics performance to have a higher social status. Our results show that both dimensions carry a substantial weight in revealed identification preferences.

Second, we find that revealed identification preferences matter for subsequent behavior. In particular, they are systematically related to behavioral heterogeneity in group-specific social preferences as measured by dictator games. Individuals who reveal a stronger preference for identifying with their initial group discriminate more strongly between this group and other groups in allocation choices. We also find individuals discriminating not just between in- and outgroups but even among different outgroups. Strikingly, even this within-subject-heterogeneity in allocation choices is paralleled by the within-subject-heterogeneity in identification preferences: Differences in revealed identification preferences correlate with subsequent allocation choices even up to the behavioral variation towards different outgroups.

Our paper provides a novel perspective on the rapidly growing empirical literature on social identity in economics. Typical papers in this literature exogenously vary the salient identity an individual perceives while making a decision and observe a broad variety of behavioral effects. Studies like Chen and Li (2009) build on the minimal group paradigm by inducing a specific new identity due to the formation of groups based on an arbitrary assignment mechanism ${ }^{3}$ In contrast, papers like Benjamin et al. (2010) do not induce new identities but rather experimentally vary the salience of pre-existing dimensions of an individual's identity via priming methods. A shared theme among these papers and ours is that behavioral heterogeneity can be rationalized by a combination of

\footnotetext{
${ }^{3}$ The classical way to do this is to build on preferences for paintings (Tajfel et al. 1971). Deviating from the original minimal group paradigm, however, most studies then strengthen these identities by subsequent social interaction (for example by chat-supported group activities).
} 
identity-specific preferences and heterogeneous identities. However, what distinguishes our paper is to explicitly treat identification preferences as a source of heterogeneous identities. Hence, it acknowledges the potential endogeneity of identity at the individual level and the corresponding general notion of preferences for identification. So far, these aspects have largely been neglected by papers in experimental economics, despite being explored in the theoretical literature (Akerlof and Kranton 2000, Shayo 2009, Bernard et al. 2016, Akerlof 2017). The paper by Fong and Luttmer (2009) represents a notable exception: Based on representative US data, they show that the closer potential donors feel to the perceived race of donation recipients, the more they actually donate. These results nicely complement those we find in this paper, as claiming to "feel close" to a group can arguably be interpreted as a stated identification preference towards this group.

While the previous paragraph took a preference-based perspective to explain behavioral heterogeneity in the context of social identity, some papers stress other aspects of decision-making: Guala and Filippin (2017) and Filippin and Guala (2017) question the interpretation of group identity effects as being preference-based and rather suggest them to be driven by heuristics and hence subject to framing effects. Other papers focus on the role of beliefs and show how they drive heterogeneity in social identity related behavior: In Ockenfels and Werner (2014) ingroup favoritism decreases when dictators know that recipients are actually not aware of the shared group membership, which is not consistent with a pure outcome-based social preferences mechanism. Tanaka and Camerer (2016) show that beliefs about the characteristics of potential outgroups explain differences in outgroup discrimination, while Grimm et al. (2017) document that beliefs about the behavior of other groups matter. While all these papers differ in the explanation for heterogeneous social identity related behavior they put forward, none of these explanations stand in explicit conflict to ours on identification choices. For instance, even if the actual behavioral effects of social identity are rather the result of heuristics, the particular structure of these heuristics could be shaped by underlying identification decisions. Further, the results of Tanaka and Camerer (2016) and Grimm et al. (2017) are fully consistent with our framework as beliefs over the behavior and characteristics of other groups should in fact be a major determinant of the corresponding identification preferences regarding these groups. Finally, a shared feature of our paper and the latter two is the consideration of different potential outgroups and accordingly the possibility of differential outgroup discrimination, albeit the underlying mechanisms differ substantially.

In addition, the following papers are closely related to ours: Hargreaves-Heap and Zizzo (2009) study the "value of groups". Doing so, they contrast the material effects of groups in the context of trust games to their psychological effects. They document substantial "additional psychological benefits of group membership" as participants are willing to pay more to stay in their initial groups than the expected material benefits would justify. Within our framework, this could be interpreted as indicating a general preference for identification - a result we are able to confirm in our analysis. Moreover, our experiment resolves a potential design issue of their approach: As the authors state themselves, the interpretation of their findings "is complicated by a well-known wedge in experi- 
ments between the willingness-to-pay $(W T P)$ and the willingness-to-accept (WTA) compensation that can arise through, for example, the influence of reference dependence effects." (p. 297). Our within-subject approach resolves this issue and hence complements the initial findings in that paper. In addition, our paper investigates the underlying structure of the corresponding identification preferences and its behavioral consequences.

Charness et al. (2014) share with our paper the consideration of the multi-dimensionality of identity. They analyze group choice in public goods games and vary whether individual members differ in their prior social interaction (within the experiment) and whether they enter the public goods game with different endowment levels. The main result is that differences in endowment levels dominate joint group activities in driving segregation of groups. One could interpret this finding as individuals trading-off these different characteristics against each other and hence also revealing some sort of identification preference. However, given that the dominating characteristic participants care about is explicitly related to monetary payoffs and also takes place within a strategic setting (the public goods game), arguably plausible alternative interpretations seem warranted. Given our focus on the clean elicitation of identification preferences (which is not the focus of their paper), we consider the results from our experiment to be cleaner in this respect, in particular when it comes to the separation of preferences and subsequent behavior.

Kranton et al. (2018) share the spirit of our analysis in several ways. First, they also explicitly consider individual heterogeneity with respect to identity related behavior, as they classify individuals as "groupy" if they display ingroup bias independent of the particular nature of the group setting they are exposed to. This complements our findings insofar as "being groupy" could be interpreted as having quite accentuated general identification preferences. Second, they document differential behavioral effects according to this classification: Groupy individuals are more likely to affiliate themselves with a political party, which speaks to our results on the link between identification preferences and identity-related behavior. One way to compare the two papers is to note that ours considers the within-subject consistency of heterogeneity in identification preferences and subsequent behavior while the paper by Kranton et al. (2018) stresses the between-subjects heterogeneity of the general attitude towards groups which they coin "groupiness". Further, our paper complements this by explicitly considering the process underlying these different group identities, namely preferences over identification decisions of individuals.

Finally, by suggesting identification preferences as an explanation for behavior in dictator games our paper also relates to the broader literature on the existence, heterogeneity, and stability of social preferences (Andreoni and Miller 2002, Charness and Rabin 2002, Engelmann and Strobel 2004, Fisman et al. 2007, Bellemare et al. 2008, Iriberri and Rey-Biel 2011, 2013, Breitmoser 2013, Bruhin et al. 2016, and Schumacher et al. 2017). In this regard our paper advocates the consideration of identification behavior as a potential mechanism underlying the existence and heterogeneity of social preferences across settings, individuals, and time. 
The remainder of the paper is structured as follows. Section 2 provides a detailed description of our experimental design, whose results are presented in Section 3. Finally, Section 4 provides a discussion of our findings and concludes.

\section{Research Design}

Assessing the structure of identification preferences and investigating their behavioral consequences requires reliable measurements of both. Whereas discrimination in dictator games across varying recipients is routinely used to measure the latter (Chen and Li 2009), there exists no established procedure to measure identification preferences. We therefore design a novel experimental protocol to do so.

\subsection{Measuring Identification Preferences}

Our experiment allows individual choices to reflect the non-monetary utility an individual derives from identification. These choices should thereby reveal identification preferences in an incentivecompatible way. Our approach first categorizes participants into several different groups. Subsequently, they face the possibility of re-assignment to any of the other groups. Using the BeckerDeGroot-Marschak (1964) value-elicitation procedure (BDM), we elicit each individual's monetary payment required to accept this re-assignment for any particular group. We assume that a stronger identification preference for some specific group characteristic corresponds to a higher required payment to join a group that actually holds this characteristic. Under this assumption, our procedure elicits the structure of identification preferences.

Analyzing the structure underlying identification preferences requires exposing participants to a rich and meaningful set of alternative groups while keeping full control in a laboratory setting. To provide such a setting, we apply two different group assignment rules, which are particularly designed to capture social distance as well as social status. As a result, each group carries not just one but two different characteristics. This allows us to observe differences in identification preferences not only between one's own ingroup and outgroup, but also across different outgroups with different characteristics 4

Importantly, the laboratory environment permits us to explicitly control the monetary benefits and instrumental values associated with the different groups in our experiment. To that end, monetary

\footnotetext{
${ }^{4}$ Groups of higher social status facilitate favorable comparisons to other groups (Tajfel et al. 1971, Tajfel 1972, 1978, and Tajfel and Turner 1979). Thus, individuals should seek to identify with groups of high status (Tajfel 1974). Social distance refers to the notion that identifying comes more naturally for an individual if her own actual characteristics match this category's stereotypes (Akerlof and Kranton 2000). Hence, individuals should, ceteris paribus, prefer to identify with groups whose defining characteristics are more similar to their own. Social distance is thus also related to the concept of homophily (McPherson et al. 2001, Girard et al. 2015, and Currarini and Mengel 2016).
} 
incentives are muted in all stages unrelated to the elicitation of preferences for identification and identity-contingent discrimination. We thereby avoid that these decisions are affected by income effects arising from prior stages, feelings of generalized reciprocity due to group performance-related payoffs (Yamagishi and Kiyonari 2000) or strategic considerations for upcoming stages.

\subsection{Experimental Design}

The experiment consists of five stages. Groups are assigned and characteristics are formed and enhanced in the first two stages. In the third and fourth stages, we measure identification preferences and group-specific dictator game behavior, respectively. The fifth and final stage merely increases the psychological relevance of identification. Figure 1 shows the timing of the experiment as well as the information provided to the participants at the beginning of each stage $5^{5}$ Prior to the main experiment, we conducted a pilot study which included the same experimental stages, but deviated with respect to some details. We discuss the results of this pilot study briefly in Section 3.3 and provide further details in Appendix B.

\section{Stage 1: Group Assignment and Identity Formation}

We conduct the experiment simultaneously in two laboratories. Participants' affiliation with one of two German professional football clubs serves as a first assignment rule to different groups. The participants are either supporters of Eintracht Frankfurt or 1. FC Köln. We specifically choose these two clubs as they share a long history in German professional football and mirror each other quite closely in terms of their historic as well as recent performance ${ }^{6}$ which reduces the scope for additional social status concerns. Within the groups of participants from each football club, we add a second group dimension by sorting participants according to their performance in a real-effort task. Following Bartling et al. (2009), we ask participants to solve as many arithmetic problems (adding three two-digit numbers) as possible in 90 seconds. We assign participants whose performance exceeds the median number of correctly solved math problems among supporters of their club in that session to the green group of their club and those with an inferior score to the orange group of their club.7

Conditional on their performance in the math task and their affiliation with the two football clubs, we then assign participants to non-overlapping groups of four: (i) a group of high performance (green) from Eintracht Frankfurt, (ii) a group of high performance (green) from 1. FC Köln, (iii) a group of low performance (orange) from Eintracht Frankfurt, and (iv) a group of low performance (orange) from 1. FC Köln. Using football club affiliation and performance in a real effort task for group assignment provides scope for social distance as well as social status to affect the individu-

\footnotetext{
${ }^{5}$ The instructions are provided in Appendix C.

${ }^{6}$ Both were founding members of the German Bundesliga, played around 1550 Bundesliga matches, and are ranked 9th and 10th in the all-time table. The historical performance of both clubs was very similar at the time when we conducted the experiment. Each of them won the German cup (DFB-Pokal) four times. Köln was relegated to the 2nd division (and afterwards promoted again to the Bundesliga) five times, Frankfurt four times.

${ }^{7}$ We choose group colors such that they do not share any of the official colors of either of the two clubs.
} 
als' identification in both dimensions 87 To emphasize the status-component of the real effort task even further, participants' screens display a winner's podium with the green group on top and the orange group standing next to it. The corresponding message says that participants assigned to the green group belonged to the top half of the participants from their football club in that session. Accordingly, participants in the orange group are informed that their performance is in the bottom half within their group of supporters.

We inform participants about the group assignment and the content of the following stage only after the completion of the real-effort task. Thus, when completing the task participants have no information about its purpose. This ensures that strategic considerations based on the ensuing task do not factor into the effort decision and thereby not actively influence group assignment. The performance in the math-task is not incentivized to rule out that the elicitation of preferences for identification is affected by prior earnings.

\section{Stage 2: Group Enhancement}

Recent evidence shows that studying identity successfully in the laboratory may often require enhancement through some joint activity (e.g. Eckel and Grossman 2005, Chen and Li 2009, Chen and Chen 2011). We therefore engage participants in a group-quiz. The quiz consists of three quartets of pictures. For each of these three sets of four pictures, groups have to find an umbrella term and have 60 seconds to discuss the solution via the chat program 99 Participants then enter their answers individually $\sqrt{10}$ Even though we do not incentivize correct answers and do not provide feedback about the solutions to preclude that performance in the group task affects identification, all participants actively engaged in all of their group's problems and entered at least one line per quiz.

\section{Stage 3: Elicitation of Revealed Identification Preferences}

In a first step, each of the four groups is attached a randomly drawn monetary value

$$
\pi_{d, s}, d \in\{\text { Eintracht Frankfurt, 1. FC Köln }\}, s \in\{\text { high performance, low performance }\},
$$

between 0 and 8 Euro, but not yet revealed to the participants 11 Importantly, to elicit clean

\footnotetext{
${ }^{8}$ Note that the overwhelming majority of participants perceive the reputation of the two football clubs to be about equal. This suggests that there is no status difference between football clubs.

${ }^{9}$ Participants are prohibited to discuss personal information during the chat phase and are informed that violation of this rule would result in expulsion from the experiment. Aside from this constraint, conversations are unrestricted. Chat-logs reveal that there was no communication about personal information. Since participants had no information about subsequent stages at the time of the group chats, they were also unable to discuss their choices in the following tasks in advance.

${ }^{10}$ Although participants are not bound by the prior group discussions, the chat-log reveals that almost all participants entered the group consensus in the chat.

${ }^{11}$ Throughout the paper, index $d(s)$ refers to groups of supporters of the same football club (performance), whereas $-d(-s)$ refers to groups of supporters of the other football club (performance) from the perspective of the respective participant.
} 
identification preferences, group membership must not entail any other potential strategic benefits. The monetary group values are therefore independent of the groups' prior performance in the math task and group-quiz, so that different monetary values cannot give rise to feelings of guilt, spite, or reciprocity towards other group members.

Based on these group values, we request participants to state the minimum difference in the payment they would receive as a member of their own group and any other group, i.e. $W T A_{k}, k \in$ $\{(d,-s),(-d, s),(-d,-s)\}$, they demand to accept a re-assignment to the respective group for the remainder of the experiment ${ }^{12}$ Simply asking participants for their WTAs might artificially inflate the $W T A$ s because participants might feel compelled to add a positive number. We therefore use scrollbars ranging from -8 Euro to +8 Euro. This highlights the possibility that stating a negative $W T A$ (i.e. expressing to prefer another group to the initial one) is possible and allows us to specify a default, which we set at 0 .

A purely money-oriented individual would be willing to accept re-assignment to any other group if the group's monetary value exceeds the one of her own group, given the information that the ensuing task in the new group does not yield any monetary benefits. The stated minimum difference for such an individual should thus be zero. We interpret any deviation in the stated $W T A_{k}$ as a revealed identification preference as there are no other potential motives by design 13

Out of the four groups, one participant is randomly selected for actual re-assignment to a random group. She is re-assigned to that group $k$ only if the stated $W T A_{k}$ is equal to or below the actual difference in monetary values between the respective groups ${ }^{14}$ Importantly, by restricting the number of participants who can be re-assigned to one, the choice of the WTAs does not depend on participants' beliefs about the behavior of the other participants, because participants are assured that the characteristics and composition of the other groups do not change apart from their own potential entry.

In order to make the payoffs in the third stage even more salient and ensure that every participant understands the payoff consequences of her decisions, we include comprehension questions which focus on the optimal strategy given a certain objective. More specifically, every individual has to state the optimal strategy for three types of individuals: (i) an individual who would like to remain

\footnotetext{
${ }^{12}$ As an illustration, an individual who states a positive $W T A_{k}$ would accept re-assignment to that group only if the payoffs of group $k$ exceed the payoffs of her own group at least by the stated amount, i.e. if $\pi_{k}-\pi_{d, s} \geq W T A_{k}$. If the difference in payoffs between the two groups would fall below that level, she would prefer to remain with her initial group, even if the payoff of the other group is larger.

${ }^{13}$ Becker et al. (1964) show that this mechanism is incentive-compatible. There has been a recent debate on the reliability of the BDM mechanism for the measurement of WTP-WTA gaps to identify reference-dependence (Cason and Plott 2014, Bartling et al. 2015). However, given that our main results focus on within-participant differences between different $W T A s$, our approach appears robust towards these concerns.

${ }^{14}$ For example, if the group of the same football club, but different status was selected for re-assignment, the participant would only be re-assigned if $\pi_{d,-s}-\pi_{d, s} \geq W T A_{d,-s}$ holds.
} 
with her initial group, (ii) one who would like to leave her initial group, and (iii) one who does not care about group membership and wants to maximize her own payoffs.

\section{Stage 4: Two-Person Dictator Games}

Before revealing the outcome of the random draws from the third stage, i.e. the realizations of the attached monetary group values and whether they are re-assigned to another group, we ask every participant to make a series of decisions in dictator games to elicit group-specific social preferences. Individuals are matched in pairs of two. There are two roles: dictator and receiver. The dictator is endowed with 10 Euros, whereas the receiver is given 5 Euros. The dictator can now share some of her endowment with the receiver, take some of the endowment from the receiver, or leave both players with the initial endowment. Giving or taking is restricted to increments of 10 Cents. Every Cent given to the receiver is doubled by the experimenter, every Cent taken from the receiver is halved by the experimenter. Thus, giving (taking) is efficient (inefficient). We implement this design feature for two reasons. First, starting with the seminal paper written by Tajfel et al. (1971), a similar payoff structure is frequently used in studies on ingroup bias conducted by social psychologists. Second, including the efficiency component makes outgroup discrimination less attractive for individuals who care about efficiency. Observing outgroup discrimination in this type of decision will therefore be a stronger result than in a standard dictator game because favoring the ingroup member inevitably yields a loss in efficiency.

Just as in the group selection stage, we use the strategy-method to collect decisions for all groups. Every individual has to choose an allocation between herself and another member of each of the three other groups as well as between herself and a member of her own group. For each participant, one game, one role (dictator or receiver), and one partner is randomly selected for payment at the end of the experiment. Importantly, members are matched based on the initial group assignment. This means that by switching groups in stage 3, a participant cannot affect the monetary payoff resulting from stage 4 .

\section{Stage 5: Picture Quiz}

Ultimately, participants play the second sequence of picture puzzles. This happens after the realizations of the monetary group payoffs of all four groups, the group which has been selected for re-assignment, and information about the potential new group composition are revealed. The procedures are identical to stage 2 . If the randomly selected individual accepted re-assignment by stating a sufficiently low $W T A$ for the randomly selected group, she performs the quiz as a member of her new group. Correct solutions to the picture puzzles are again not incentivized, which is also clearly pointed out in the instructions. 


\subsection{Experimental Procedures}

We conducted three independent computerized sessions using z-Tree (Fischbacher, 2007). The sessions were run simultaneously at the Frankfurt Laboratory for Experimental Economic Research (FLEX) and the Cologne Laboratory for Economic Research (CLER) in August 2016. To ensure that supporters of the two clubs participated in the experiment, we targeted football fans within the subject pools and asked only supporters of the two clubs to sign up at the respective university. The participants sharing the same two characteristics were randomly divided into groups of four. Thus, each of the four groups was represented twice or thrice per session 15 To channel the participants' focus on the two different dimensions of identity, the respective football club's logo was displayed on all screens on the top right, while a group box at top center of the screen reminded them of their assignment to either the green or orange group. The logo and the group box were removed on the group selection screen.

In total, 128 participants took part in our experiment. Sessions lasted from 75 to 90 minutes. Including the show-up fee of $€ 4$ paid to every participant, participants on average earned $€ 17.42$, with the minimum at $€ 7.50$ and the maximum at $€ 35.20$. Instructions were split into four parts and distributed sequentially. Participants had to answer two sets of control questions prior to stages 3 and 4 before they made their decisions. After completion of the five stages, the experiment concluded with a post-experimental questionnaire.

\section{Results}

We present our results in three parts. First, we focus on revealed identification preferences and their structure, more specifically the role of social status and social distance (Section 3.1). Then, we analyze how these identification preferences affect subsequent behavior in group-specific dictator games (Section 3.2). Finally, we discuss potential concerns and alternative explanations as well as the results from the pilot study (Section 3.3).

\subsection{Revealed Identification Preferences}

Figure 2 displays the average stated $W T A s$ for each of the three outgroups as well as the average $W T A$ over all three groups (black bar) for all 128 participants. For an overwhelming majority of the participants, group affiliation holds sizeable value. On average, participants require a differential of 221.51 Cents between the payoffs of their own group and the payoffs of the other groups to accept re-assignment to another group. This value is not just statistically different from 0 (t-test: $p<0.0001$ ), but also economically meaningful as it amounts to $55.4 \%$ of a participant's expected earnings of 4 Euro from the group selection stage. Table 1 also shows that all outgroup-specific

\footnotetext{
${ }^{15} 24$ individuals took part per laboratory in one session, while 20 individuals took part per laboratory in two other sessions due to no-shows. In the latter two sessions, we have 3 high status groups and 2 low status groups per football club.
} 
WTAs are significantly larger than 0 . Notably, for only $26.6 \%$ of the participants groups do not matter (average $W T A$ of 0 ). Two participants state a negative $W T A$ average for all three outgroups. However, while the WTA median is 142.44 Cents, 22.7 percent of the participants even state average $W T A$ s larger than 4 Euro. These results support the view that there is much heterogeneity with respect to the perceived importance of groups, i.e. that some people are more "groupy" than others (Kranton et al. 2018).

Positive valuations of own group membership could simply reflect a status quo bias and thus some sort of endowment effect with respect to the "endowed" initial group (Kahneman et al. 1986, Knetsch 1989, Hargreaves-Heap and Zizzo 2009). To rule this out, we exploit the within-subject structure of our design and compare WTAs across different outgroups. In our experiment, a potential endowment effect would equally apply to all three outgroups and could therefore not explain differences in WTAs across outgroups. At the individual level, we find that 58.6 percent of the participants $(n=75)$ state different $W T A s$ for at least two of the three outgroups. This share even increases to 79.4 percent when focusing only on those participants stating a $W T A>0$. Differences in identification across groups are not just sizable in terms of frequency, but also with respect to magnitude (see Figure 3). The average standard deviation in WTAs across groups amounts to 83.99 Cents or 37.9 percent of the average stated $W T A$. Given this substantial variation, we are confident that our results do not merely capture status quo bias, but reflect preferences for identification. Result 1 summarizes our findings up to this point:

Result 1: Identification matters. Participants are willing to forfeit a significant amount of money to join or stay in a particular group despite the lack of any material incentive to do so, thus revealing significant identification preferences.

Our within-subject design also facilitates examining the particular structure of revealed identification preferences. Making use of our specific group assignment rules, we investigate whether revealed identification preferences in our experiment are in accordance with the theoretical foundations laid out in the social identity literature. More specifically, we ask whether we can organize identification preferences along two key dimensions of identification suggested by social psychology - social distance and social status.

To gauge the impact of social distance, we utilize the football club dimension of our group assignment. Participants' football club affiliation constitutes a natural source of perceived social distance in this particular aspect. We contrast an individual's WTAs for the two outgroups with the other math performance of the same football club and the other football club 16 Varying only the football club affiliation of a group while holding math performance (social status) fixed allows to isolate the former's effect. Panel (a) of Figure 4 shows the WTAs for the two groups. The graph indicates

\footnotetext{
${ }^{16}$ E.g., for an individual with high performance in the math task, we compare the WTAs for the two low performance groups of the same and the other club.
} 
that social distance matters. The average $W T A^{\text {Distance, }}$, i.e. $W T A_{-d,-s}-W T A_{d,-s}$, is 36.72 Cents. Put differently, participants require roughly 37 Cents more to accept being re-assigned to the group from the other football club (grey bar) compared to the one from the same football club (black bar) (two-sided t-test: $p=0.0338)$

We apply the same strategy to identify the role of social status. Group assignment based on performance in a skill-based task like solving math-exercises induces social status in the sense that a higher performance is superior compared to a low performance. By focusing on the two outgroups from the other football club, we hold football club affiliation (social distance) fixed and only vary math performance. Panel (b) of Figure 4 shows participants' average $W T A$ with respect to the group of the other club and high status (dark grey bar) and the group of the other club and low status (white bar). Computing $W T A^{\text {Status }}=W T A_{-d \text {,low math performance }}-W T A_{-d \text {,high math performance, }}$, we find that the average difference between these two groups amounts to 71.19 Cents and is both economically (almost $18 \%$ of the expected payoff from that experimental stage) and statistically highly significant ( $p=0.0009$ in a two-sided t-test).

Result 2: Social distance and social status matter. Participants prefer to identify with groups (a) to which they have a lower social distance and (b) that have a higher social status.

Individuals differ in their valuation of social status contingent on their own performance. Whereas the average $W T A^{\text {Status }}$ amounts to 88.17 Cents for members of the high performance groups $(p=$ 0.0113 in a two-sided t-test), it is only 49.36 Cents for those in the low performance groups $(p=$ 0.0165 in a two-sided t-test), as can be seen in Figure 7. While this difference is sizeable in economic terms, it is, however, not statistically significant ( $p=0.3607$ in a two-sided t-test). We cautiously interpret this indication of an asymmetry in the average importance of social status as being in line with theoretical arguments raised by Wichardt (2008) and Akerlof (2017). Wichardt (2008) suggests that when confronted with multiple dimensions of group characteristics, an individual's focus on a particular group increases in its positive contribution to their identity in a certain context. Similarly, Akerlof (2017) argues that individuals manage identity by reweighting "achievements" in different dimensions. In line with that, an experimental study by Paetzel and Sausgruber (2018) finds that ingroup bias is more pronounced in high-performing groups. We provide a more detailed account on this and on heterogeneity in social distance and social status in Appendix A.

\subsection{Behavioral Effects of Identification Preferences}

We now investigate the relation between identification preferences and subsequent behavior and test whether the observed variation in identification preferences translates into heterogeneity in groupspecific social preferences measured in the dictator game decisions in stage 4 of our experiment.

\footnotetext{
${ }^{17} W T A^{\text {Distance }}$ does not significantly vary across the two clubs (two-sided t-test: $p=0.6415$ ). Figure 7 depicts the corresponding mean values (44.73 Cents for Eintracht Frankfurt and 28.71 Cents for 1.FC Köln).
} 


\subsubsection{Preferences for Identification and Allocation Choices: Ingroup vs Outgroups}

We start by comparing discrimination in allocation choices between a member of one's own group and a member of the three different outgroups. In a first step, we define outgroup discrimination as choosing a less favorable allocation for a matching partner from one of the three outgroups compared to the one from the ingroup in the dictator game decisions. According to this definition, 60 of 128 participants (46.9\%) discriminate in their allocation decisions.

The share of individuals discriminating against outgroups is substantially higher for participants with a high average $W T A$. Whereas 56.3 percent of the participants whose average $W T A$ is above the median discriminate against outgroups, the corresponding share is only 37.5 percent for participants with a WTA average below the median (see also panel (a) of Figure 5). This difference is statistically significant (Pearson- $\chi^{2}$-test: $p=0.034$, Fisher's exact test two-sided: $p=0.051$ ).

Columns (1) and (2) of Table 2 augment the result presented above. They report average marginal effects for logistic regressions of outgroup discrimination in allocation choices at the individual level on preferences for identification and a set of socio-demographic controls. The dependent variable is a dummy variable that takes the value of 1 if a participant discriminates against at least one outgroup in the allocation decisions and is 0 otherwise. We control for a participant's age, gender, and the enrollment status (using a dummy variable that is equal to 1 if the participant is enrolled in a bachelor program, and 0 otherwise). Standard errors are clustered at the group level and reported in parentheses. In column 1, identification preferences are measured using a median split of average $W T A$ over the three outgroups. Closely mirroring the raw difference, individuals whose average $W T A$ is above the median level are 19 percentage points more likely to discriminate against at least one outgroup. The marginal effect is statistically significant at the $10 \%$-level $(p=0.053)$. In column (2), we employ the average stated WTA measured in Euros over all three alternative groups as a more detailed, intensive margin measure of the degree of identification. While the marginal effect has a positive sign, it remains statistically insignificant at conventional levels. The extensive margin effect reported above can, thus, not be found at the intensive margin. However, using $W T A$ as explanatory variable assumes a linear relationship between $W T A$ and the probability to discriminate against outgroups which appears quite restrictive. Additionally, the dependent variable in the estimations is a dummy variable - which does not allow to investigate heterogeneity in dictator game giving at the intensive margin. The next step of our analysis therefore exploits the within-subject dimension in order to get a more comprehensive picture.

Our experimental design allows not only to focus on the aggregate level, but also on specific groups. We can analyze allocation choices at the group level, taking into account unobserved heterogeneity by including participant fixed effects. The dependent variable in the according estimations (see Table 3) captures the amount sent to the receiver in the dictator game (contingent on the receiver's group membership) measured in Cents. Our explanatory variable of main interest captures pref- 
erences for identification with the receiver's group. It equals the group-specific WTA (measured in Euros) for outgroup receivers and is 0 if the receiver stems from the ingroup. The fixed-effects estimations show that the stronger identification preferences with respect to the receiver's group are, the larger is the amount sent by a participant. Column (1) reveals that the amount sent to a receiver decreases by 12.83 Cents for every 100 Cents increase in the stated WTA with respect to this receiver's group. In column (2) we add two dummy variables to control for outgroup characteristics (i.e. other football club and low performance) 18 The regression results reveal that individual identification preferences still have a significant effect on discrimination decisions in allocation choices - even if we control for the exogenous group characteristics. This highlights the relevance of heterogeneous identification preferences as a relevant source of variation in individuals' social identity.

Result 3: Identification preferences explain ingroup-outgroup discrimination. Individuals who identify more strongly with their initial group (who have an above-median average WTA) are more likely to discriminate against outgroups in allocation choices. A given participant treats an outgroup member less favorable in the dictator game, the lesser she identifies with this particular group (the higher her WTA towards this outgroup).

\subsubsection{Preferences for Identification and Allocation Choices: Between Outgroups}

Our design allows for an additional complementary test of Result 3: We can check whether differences in the revealed preferences for identification among outgroups parallel differences in the allocation choices among outgroups.

Looking at the share of participants who discriminate in allocation choices between the three outgroups, we find that this share is significantly higher for individuals who also display differences in their identification with the three groups (see panel (b) of Figure 5). Out of these 75 participants, 61.3 percent allocate different amounts of money across at least two outgroups in the dictator game, while only 26.4 percent of the 53 individuals who state equal $W T A$ s for the three outgroups do so. This difference is highly statistically significant $(p<0.001$ in both a two-sided Fisher's exact test and Pearson- $\chi^{2}$-test) and virtually unaffected once we control for socio-demographic factors in a regression. The estimated average marginal effect of identification is 36.8 percentage points (column (3) of Table 2).

Our experimental design allows to again exploit the within-subject dimension and to investigate whether participants who differ in their identification (WTA) with two specific outgroups discriminate between exactly these outgroups in the dictator game. We now consider pairwise comparisons

\footnotetext{
${ }^{18}$ Column (2) of Table 3 includes two dummy variables to control for outgroup characteristics. Outgroup - Other $C l u b$ indicates whether an outgroup stems from the other football club, while Outgroup - Low Performance takes on the value of 1 for outgroups of below median performance in the math task.
} 
of two outgroups each, yielding three observations per individual in total ${ }^{19}$ Columns (3) and (4) of Table 3 present coefficient estimates of OLS regressions, using the difference in WTAs between the respective outgroups as the explanatory variable. The dependent variable is equal to the difference in the amounts given to the recipients in the dictator game for the according pair of outgroups 20 Mirroring our previous results, differences in identification preferences are once again related to differences in discrimination in allocation decisions. If identification preferences regarding outgroup $A$ are stronger than regarding $B$ (implying a negative $W T A$ difference), the payoff assigned in the dictator game to the member of outgroup $A$ is higher. The Identification Preference coefficient in column (3) reveals that a 100 Cents higher WTA difference between two outgroups increases dictator game discrimination between the two groups by 10.45 Cents. This estimate is unaffected when we control for socio-demographic information in column (4). Heterogeneity with respect to identification preferences thus translates into heterogeneity with respect to allocation choices regarding different outgroups.

Result 4: Identification preferences explain outgroup-outgroup discrimination. Individuals whose identification preferences differ among outgroups are more likely to discriminate in their allocation decisions between outgroups. Differences in identification preferences between a particular pair of outgroups explain differences in the degree of discrimination between these outgroups at the within-subject level.

\subsection{Discussion and Pilot Study}

The results presented thus far are in line with the conjecture that both social distance and social status shape identification preferences and that heterogeneity in these preferences is related to subsequent behavioral heterogeneity. We have demonstrated that (i) group identification matters, as participants are willing to forego a significant amount of money in order to remain a member of a particular group, that (ii) the structure of the participants' revealed identification preferences can be organized along social distance and social status, two key identity dimensions proposed by social identity theory, and that (iii) a weaker identification preference towards a certain group translates into a less preferential treatment. We now discuss some alternative explanations and interpretations and refer to the above-mentioned pilot study. A more detailed discussion of the pilot study results is provided in Appendix $\mathrm{B}^{21}$

\footnotetext{
${ }^{19}$ For each participant, we compare (1) the two outgroups from the other club, (2) the outgroup from the own club and the outgroup of the same color but other club, and (3) the outgroup from the own club and the outgroup of the other color and other club.

${ }^{20}$ The chosen estimation model is in first differences as we are interested in within-participant differences between outgroups. In contrast to the fixed effects estimations reported in columns (1) and (2) of Table 3 we can therefore additionally include time-invariant participant-specific control variables as a robustness check in column (4).

${ }^{21}$ Table 4 provides an overview of the key features and differences of the two experiments. In short, all of our main findings are in line with those from the main experiment: We find that identification matters (Result 1), social distance and a group's social status matter for identification (Result 2), and identification predicts group specific social preferences (Results 3 and 4 ).
} 


\section{Elicitation Procedure}

Irrespective of the sizable variation in the participants' stated WTAs across groups (see Figure 3), one might argue that our measures of identification preferences might depend on the chosen elicitation procedure. In the pilot study, we made use of textboxes instead of the scrollbars utilized to elicit WTAs in the main experiment. For each outgroup, the participants simply typed in the minimum payoff difference for which they would be willing to change groups. There was no default value in the pilot (whereas the scrollbar was adjusted at 0 in the main experiment by default). Furthermore, with the textbox, the possibility that stating a negative $W T A$ (i.e. expressing to prefer another group to the initial one even if this other group earns less money) was viable might have been less clear to the participants. In fact, the share of individuals who are purely money-oriented and do not care about group affiliation was smaller in the pilot (7.8\%) than in the main experiment (26.6\%). This suggests that the elicitation procedure chosen for the main experiment is the more conservative one. Most importantly, all results hold regardless of whether we focus on the main experiment or the pilot study which makes us confident that our findings are not driven by this particular feature of WTA elicitation.

\section{Interpreting $W T A$ s as Revealed Identification Preferences}

A key feature of our design is its ability to interpret stated WTAs as reflecting pure identification preferences. This ability hinges upon stripping away the consequences of group re-assignment of any potential alternative motive other than identity. For this reason, we made the last round of the experiment - the second chat phase which is potentially carried out in the new group - anonymous and non-incentivized and explicitly informed participants about this. Despite this design feature, one might argue that the second chat phase could still induce motives for group-reassignment other than identity. We tackle this alternative explanation by re-running our analysis for the subset of 102 participants who stated in the post-experimental questionnaire that the second chat phase had no or only low relevance. For these participants, average $W T A$ is smaller than in the full sample, but still amounts to 194.45 Cents, i.e. $48.6 \%$ of the expected earnings from that stage, and highly significantly different from 0 ( $p<0.0001$ in a two-sided t-test). The impact of social distance and social status is also slightly reduced in this subsample. Average $W T A^{\text {Distance }}$ is 26.78 Cents $(p=0.1924)$ compared to 36.72 Cents in the full sample, while average $W T A^{\text {Status }}$ equals 54.10 Cents $(p=0.02)$ compared to 71.19 Cents in the full sample.

\section{Dictator Game Structure}

We also probed the association between identification preferences and discrimination in the allocation decisions by varying the action space in the latter. The dictator game design in the main study involved an efficiency component, i.e. favoring the ingroup member was inefficient. Starting with Tajfel et al. (1971), dictator games with an efficiency component have been commonly used in experiments in social psychology. The (in)efficiency component tends to make the interpretation

of existing ingroup bias even stronger. However, in the pilot study, we used simpler versions of the dictator game and limited participants' actions to four binary decisions (taken from Bartling 
et al. 2009). Whereas this setup might cloud heterogeneity in discrimination behavior for those participants who would like to discriminate at an intermediate level between the two binary options (which is why we used the continuous dictator game in the main experiment), it is instructive to compare the results from the two approaches. Indeed, this design change affects discrimination in the dictator game both at the intensive and extensive margin.

Whereas in the main study, $46.9 \%$ of the participants discriminated against at least one outgroup in the dictator game (ingroup-outgroup discrimination), this share is slightly lower in the binary dictator games (41.7\%). Discrimination between outgroups by a given individual also decreases especially among those participants who do not discriminate between outgroups with respect to $W T A$. In the main study, $26.4 \%$ of this subgroup discriminate among outgroups in the dictator game, while only $6.6 \%$ do so in the pilot study (see Figures 5 and B.4). Among those who discriminate among outgroups with respect to $W T A$, the difference between the shares of dictator game discriminators is smaller ( $49.6 \%$ in the pilot study compared to $61.3 \%$ in the main experiment). These results suggest that the continuous dictator game has its advantages in allowing participants an "intermediate level" of discrimination in allocation choices. We used the continuous dictator game in the main experiment because the expected larger within-subject variation additionally allows us to include participant fixed effects in our regression analyses, which absorb any unobserved heterogeneity that might drive allocation decisions $\sqrt{22}$ Overall, the results from the pilot and the main experiment are very consistent. We therefore conclude that the chosen dictator game structures do not drive our main findings.

\section{Role and Interpretation of Social Distance}

Although $W T A^{\text {Distance }}$ is statistically highly significant and clearly confirms the hypothesized role of social distance for identification, its impact appears to be smaller in economic terms than that of $W T A^{\text {Status }}$. A more detailed analysis reveals that heterogeneity in the individuals' responses to social distance conceals its strength in the previous aggregate analysis. Panel (a) of Figure 6 displays the average difference in WTAs in the social distance dimension. The difference of 36.72 Cents (black bar, t-test: $p=0.0338$ ) between the group of the same football club and different performance and the corresponding one of the other football club amounts to about 9.2 percent of the expected earnings in this stage. Once we restrict our analysis to those 63 individuals who actually discriminate between the two groups, the difference in WTAs becomes much more pronounced and is also economically highly significant. 46 individuals identify more strongly with their own football club, requesting 159.74 Cents (39.9 percent of expected earnings) more to accept re-assignment to the group of the other football club (grey bar). 17 participants on the other hand state a higher $W T A$ for the group from their own club compared to the group of the other club (white bar). Their average difference amounts to 155.76 Cents (or 38.9 percent of expected earnings). A more detailed analysis of this heterogeneity and a discussion are provided in Appendix A.

\footnotetext{
${ }^{22}$ In the pilot study, using fixed effects leads to a substantial reduction of the sample as there is a significant number of individuals who do not discriminate between outgroups due to the binary nature of the dictator game decision.
} 
The pilot study also helps to understand the role of social distance. In the pilot study, we chose an emotionally less charged characteristic than football club affiliation to induce differences in social distance: participants' university affiliation. Unlike in the US, where university affiliation is arguably a common source of pride, the emotional attachment is much lower in the German system. One likely reason is the fact that college sports and intercollegiate competition, which fuels rivalries across schools, is nearly non-existent in Germany. Indeed, the relative importance of social distance compared to the social status dimension turns out to be smaller in the pilot than in our main experiment. The fact that we observe significant identification preferences with respect to social distance in two separate experimental studies and different characteristics (football club as well as university affiliation) supports the claim that social distance plays a significant role in shaping identification preferences. Further, the relative effect size across the two experiments is also in line with the relative strength of the induced social distance.

\section{Role and Interpretation of Social Status}

One could question our interpretation of differences in $W T A^{\text {Status }}$ as revealing differences in identification preferences with respect to status: In principle, a preference to belong to a high performance group could also stem from social status concerns independent of group affiliations. However, in our particular experimental setup, this concern appears to be without harm: The individual status an individual holds with respect to math ability is not affected by switching groups. After the group assignment phase, each individual receives feedback on whether the individual math performance was above or below the median. By switching groups, this individual performance and hence individual status does not change - only the status of the group to which the participant is assigned to is higher or lower than the status of the initial group. In addition, if the differences in $W T A \mathrm{~s}$ that we interpret as revealed identification preferences would in fact not be related to identification preferences, one would need to find an alternative mechanism that explains its association with subsequent discrimination behavior.

Further, one might argue that within-group status considerations might also play a role in our setting. Choosing a high performing group might enhance status, but it might at the same time yield negative feelings stemming from within-group comparisons. In that sense, being a big fish in a small pond might be better than being a small fish in a big pond. As the participants in our experiment did neither receive feedback about their rank within their group nor about their absolute performance in the mathematics task (and the other participants' performance), there is actually no scope for such a mechanism. From an empirical perspective, our results indicate that our implicit assumption of participants taking an intergroup perspective when considering social status seems warranted: If the small pond would be overly attractive, the WT $A^{\text {Status }}$ effect should go into the opposite direction than it actually does. For future research, it will be worthwhile investigating the potentially different effects of individual and group status in a similar setting. To do so, it would be necessary to provide the participants with information about their own relative 
performance compared to the other group members.

\section{Conclusion}

This paper investigates how individuals want to identify with different groups using a revealed preference approach. We then test whether these revealed preferences for identification are related to behavior in the domain of social preferences as measured by allocation decisions in group-specific dictator games.

We find that individuals display economically meaningful and substantially heterogeneous preferences for identification and are willing to forego significant monetary payments in order to manipulate their group membership. In line with the predictions from social identity theory, we find that participants prefer more strongly identifying with groups that have a higher social status and to which they have a smaller social distance. Further, we find that identification preferences matter for behavioral heterogeneity. Participants with stronger identification preferences towards their initial ingroup also discriminate more strongly between this ingroup and other groups in allocation choices. Our experimental design additionally allows us to analyze the within-subject-dimension of allocation choices. Notably, we find a strong connection between the within-subject heterogeneity in identification preferences and the within-subject heterogeneity in social preferences. Individuals consistently consider the specific identity-related characteristics of groups across different domains. The results from our main experiment are supported by the results from a pilot study which used a slightly different experimental design.

The observed consistency in revealed identification preferences and discrimination behavior shows the behavioral relevance of considering social identity as an endogenous choice instead of a purely exogenous characteristic. The presented findings provide insights into how individuals make these important identification decisions as they trade-off monetary gains and identity utility.

From an applied perspective, our results provide a novel angle to better understand when and how common group membership can shape behavior, when it does not, and what the underlying mechanism behind these different effects might be. It thereby also helps to assess the effectiveness of attempts to increase identification with organizations and in other economically relevant domains aiming at utilizing the potentially beneficial effects of common group identities. Our paper thus also helps in understanding why increasing the level of identification with a particular group might not be that easy. For example, Carell et al. (2013) find that some individuals tend to avoid interacting with certain peers with whom they were intended to interact by organizational design. According to our results, strengthening the general feeling of belonging to groups can rather be achieved by shaping the salient characteristics of the particular group such that they match the respective identification preferences of the relevant individuals more closely. As our study shows, social distance and social status appear as particularly promising dimensions to be utilized. 


\section{References}

Akerlof, Robert. 2017. "Value Formation: The Role of Esteem." Games and Economic Behavior 102: $1-19$.

Akerlof, George A., and Rachel E. Kranton. 2000. "Economics and Identity." Quarterly Journal of Economics 115 (3): 715-53.

Akerlof, George A., and Rachel E. Kranton. 2002. "Identity and Schooling: Some Lessons for the Economics of Education." Journal of Economic Literature 40 (4): 1167-1201.

Akerlof, George A., and Rachel E. Kranton. 2005. "Identity and the Economics of Organizations." Journal of Economic Perspectives 19 (1): 9-32.

Algan, Yann, Thierry Mayer, and Mathias Thoenig. 2013. "The Economic Incentives of Cultural Transmission: Spatial Evidence from Naming Patterns across France." Working Paper.

Andreoni, James, and John Miller. 2002. "Giving According to GARP: An Experimental Test of the Consistency of Preferences for Altruism." Econometrica 70 (2): 737-753.

Bartling, Bjoern, Ernst Fehr, Michel Andre Marechal, and Daniel Schunk. 2009. "Egalitarianism and Competitiveness." The American Economic Review 99 (2): 93-98.

Bartling, Bjoern, Florian Engl, and Roberto A. Weber. 2015. "Game Form Misconceptions are Not Necessary for a Willingness-to-Pay vs. Willingness-to-Accept Gap." Journal of the Economic Science Association 1 (1): 72-85.

Becker, Gordon M., Morris H. Degroot, and Jacob Marschak. 1964. "Measuring utility by a single-response sequential method." Behavioral Science 9 (3): 226-232.

Bellemare, Charles, Sabine Kroeger, and Arthur Van Soest. 2008. "Measuring Inequity Aversion in a Heterogeneous Population Using Experimental Decisions and Subjective Probabilities." Econometrica 76 (4): 815-839.

Benjamin, Daniel J., James J. Choi, and A. Joshua Strickland. 2010. "Social Identity and Preferences." The American Economic Review 100 (4): 1913-28.

Bernard, Mark, Florian Hett, and Mario Mechtel. 2016. "Social Identity and Social FreeRiding." European Economic Review 90: 4-17.

Bertrand, Marianne, Emir Kamenica, and Jessica Pan. 2015. "Gender Identity and Relative Income within Households." The Quarterly Journal of Economics 130 (2): 571-614.

Breitmoser, Yves. 2013. "Estimation of social preferences in generalized dictator games." Economic Letters 121 (2): 192-197.

Bruhin, Adrian, Ernst Fehr, and Daniel Schunk. 2016. "The Many Faces of Human Sociality: Uncovering the Distribution and Stability of Social Preferences." Working Paper 1603, Gutenberg School of Management and Economics. 
Bursztyn, Leonardo, Michael Callen, Bruno Ferman, Saad Gulzar, and Ali Hasanaink. 2016. "Identifying Ideology: Experimental Evidence on Anti-Americanism in Pakistan." Working Paper.

Carrell, Scott E. , Bruce I. Sacerdote, and James E. West. 2013. "From Natural Variation to Optimal Policy? The Importance of Endogenous Peer Group Formation." Econometrica 81 (3): 855-82.

Cason, Timothy N., and Charles R. Plott. 2014. "Misconceptions and Game Form Recognition: Challenges to Theories of Revealed Preference and Framing." Journal of Political Economy 122 (6): 1235-1270.

Charness, Gary, and Matthew Rabin. 2002. "Understanding Social Preferences with Simple Tests." The Quarterly Journal of Economics 117 (3): 817-869.

Charness, Gary, Ramon Cobo-Reyes, and Natalia Jimenez. 2014. "Identities, selection, and contributions in a public-goods game." Games and Economic Behavior 87: 322-338.

Chen, Roy, and Yan Chen. 2011. "The Potential of Social Identity for Equilibrium Selection." The American Economic Review 101 (6): 2562-89.

Chen, Yan, and Sherry Xin Li. 2009. "Group Identity and Social Preferences." The American Economic Review 99 (1): 431-457.

Cohn, Alain, Ernst Fehr, and Michel Andre Marechal. 2014. "Business Culture and Dishonesty in the Banking Industry." Nature 516: 86-89.

Cohn, Alain, Jan Engelmann, Ernst Fehr, and Michel Andre Marechal. 2015a. "Evidence for Countercyclical Risk Aversion: An Experiment with Financial Professionals." The American Economic Review 105 (2): 860-885.

Cohn, Alain, Michel Andre Marechal, and Thomas Noll. 2015b. "Bad Boys: How Criminal Identity Salience Affects Rule Violation." Review of Economic Studies 82 (4): 1289-1308.

Currarini, Sergio, and Friederike Mengel. 2016. "Identity, homophily and in-group bias." European Economic Review 90: 40-55.

Eckel, Catherine C., and Philip J. Grossman. 2005. "Managing Diversity by Creating Team Identity." Journal of Economic Behavior 85 Organization 58 (3): 371-392.

Engelmann, Dirk, and Martin Strobel. 2004. "Inequality Aversion, Efficiency, and Maximin Preferences in Simple Distribution Experiments." The American Economic Review 94 (4): $857-869$.

Fershtman, Chaim, and Uri Gneezy. 2001. "Discrimination in a Segmented Society: An Experimental Approach." Quarterly Journal of Economics 116 (1): 351-377.

Filippin, Antonio, and Francesco Guala. 2017. "Group Identity as a Social Heuristic: An Experiment with Reaction Times." Journal of Neuroscience, Psychology, and Economics 10 (4): $153-166$.

Fischbacher, Urs. 2007. "z-Tree: Zurich toolbox for ready-made economic experiments." Experimental Economics 10 (2): 171-178. 
Fisman, Raymond, Shachar Kariv, and Daniel Markovits. 2007. "Individual Preferences for Giving." The American Economic Review 97 (5): 1858-76.

Fong, Christina M., and Erzo F.P. Luttmer. 2019. "What Determines Giving to Hurricane Katrina Victims? Experimental Evidence on Racial Group Loyalty." American Economic Journal: Applied Economics 1 (2): 64-87.

Fryer, Roland G. Jr., and Paul Torelli. 2010. "An empirical analysis of 'acting white'." Journal of Public Economics 94 (5-6): 380-396.

Girard, Yann, Florian Hett, and Daniel Schunk. 2015. "How individual characteristics shape the structure of social networks." Journal of Economic Behavior \& Organization 115: $197-216$.

Goette, Lorenz, David Huffman, and Stephan Meier. 2006. "The impact of group membership on cooperation and norm enforcement: Evidence using random assignments to real social groups." The American Economic Review 96 (2): 212-216.

Grimm, Veronika, Verena Utikal, and Lorenzo Valmasoni. 2017. "In-group favoritism and discrimination among multiple out-groups." Journal of Economic Behavior 85 Organization 143: $254-271$.

Guala, Francesco, and Antonio Filippin. 2017. "The Effect of Group Identity on Distributive Choice: Social Preference or Heuristic?" The Economic Journal 127 (602): 1047-1068.

Hargreaves Heap, Shaun P., and Daniel John Zizzo. 2009. "The Value of Groups." The American Economic Review 99 (1): 295-323.

Hogg, Michael A., and Dominic Abrams. 1988. Social Identifications: A Social Psychology of Intergroup Relations and Group Processes. London: Routledge.

Hornsey, Matthew J. 2008. "Social Identity Theory and Self-Categorization Theory: A Historical Review." Social Personality Psychology Compass 2 (1): 204-222.

Iriberri, Nagore, and Pedro Rey-Biel. 2011. "The role of role uncertainty in modified dictator games." Experimental Economics 14 (2): 160-180.

Iriberri, Nagore, and Pedro Rey-Biel. 2013. "Elicited beliefs and social information in modified dictator games: What do dictators believe other dictators do?" Quantitative Economics 4 (3): 515-547.

Kahneman, Daniel, Jack L. Knetsch, and Richard Thaler. 1986. "Fairness as a constraint on profit seeking: Entitlements in the market." The American Economic Review 76 (4): $728-741$.

Klor, Esteban F., and Moses Shayo. 2010. "Social identity and preferences over redistribution." Journal of Public Economics 94: 269-278.

Knetsch, Jack L. 1989. "The Endowment Effect and Evidence of Nonreversible Indifference Curves." The American Economic Review 79 (5): 1277-1284.

Kranton, Rachel, Matthew Pease, Seth Sanders, and Scott Huettel. 2017. "Deconstructing Bias: Individual Groupiness and Income Allocation." Working Paper. 
McPherson, Miller, Lynn Smith-Lovin, and James M. Cook. 2001. "Birds of a Feather: Homophily in Social Networks." Annual Review of Sociology 27: 415-44.

Müller, Daniel. 2017. "The Anatomy of Distributional Preferences with Different Social Identities." Working Paper.

Nunn, Nathan. 2010. "Religious Conversion in Colonial Africa." American Economic Review Papers 8 Proceedings 100 (2): 147-152.

Ockenfels, Axel, and Peter Werner. 2014. "Beliefs and ingroup favoritism" Journal of Economic Behavior \& Organization 108: 453-462.

Paetzel, Fabian and Rupert Sausgruber. 2018. "Cognitive ability and in-group bias: An experimental study." Journal of Public Economics 167: 280-292.

Shayo, Moses. 2009. "A Model of Social Identity with an Application to Political Economy: Nation, Class, and Redistribution" American Political Science Review 103 (2): 147-174.

Shih, Margaret, Todd L. Pittinsky, and Nalini Ambady. 1999. "Stereotype Susceptibility: Identity Salience ad Shifts in Quantitative Performance" Psychological Science 10 (1): 80-83.

Schumacher, Heiner, Iris Kesternich, Michael Kosfeld, and Joachim Winter. 2017. "One, Two, Many - Insensitivity to Group Size in Games with Concentrated Benefits and Dispersed Costs" Review of Economic Studies 84 (3): 1346-1377.

Tajfel, Henri. 1972. Experiments in a Vacuum. In J. Israel and H. Tajfel (Eds.), The Context of Social Psychology: A Critical Assessment. (pp. 69-122). London/New York: Academic Press.

Tajfel, Henri. 1974. "Social identity and intergroup behaviour" Social Science Information/sur les sciences sociales.

Tajfel, Henri. 1978. Differentiation between social groups: Studies in the social psychology of intergroup relations. Oxfod, England: Academic Press.

Tajfel, Henri, and John C. Turner. 1979. An integrative theory of intergroup conflict. In W. G. Austin and S. Worchel (Eds.), The social psychology of intergroup relations (pp. 33-47). Monterey, CA: Brooks/Cole.

Tajfel, Henri, Michael G. Billig, Robert P. Bundy, and Claude Flament. 1971. "Social Categorization and Intergroup Behavior" European Journal of Social Psychology 1 (2): 149-78.

Tanaka, Tomomi, and Colin F. Camerer. 2016. "Trait perceptions influence economic outgroup bias: lab and field evidence from Vietnam" Experimental Economics 19 (3): 513-534.

Turner, John C., and Rupert J. Brown. 1978. Social Status, cognitive alternatives and intergroup relations. In H. Tajfel (Ed.), Differentiation between social groups: Studies in the social psychology of intergroup relations (pp. 201-234). London: Academic Press.

Turner, John C., Michael A. Hogg, Penelope J. Oaks, Stephen D. Reicher, and Margaret S. Wetherell. 1987. Rediscovering the social group: A self-categorization theory. Oxford, UK: Blackwell.

Wichardt, Philipp C. 2008. "Identity and why we cooperate with those we do" Journal of Economic Psychology 29 (2): 127-139. 
Yamagishi, Toshio, and Toko Kiyonari. 2000. "The Group as the Container of Generalized Reciprocity" Social Psychology Quarterly 63 (2): 116-132. 


\section{Tables and Figures}

\section{Tables}

Table 1: Summary Statistics - Identification Preferences

\begin{tabular}{lccccccc}
\hline \hline & Mean & $\begin{array}{c}\text { Std. } \\
\text { Dev. }\end{array}$ & Median & $\begin{array}{c}\text { Lower } \\
\text { Quart. }\end{array}$ & $\begin{array}{c}\text { Upper } \\
\text { Quart. }\end{array}$ & Min & Max \\
\hline$\overline{W T A}$ & $221.51^{* * *}$ & 254.65 & 142.44 & 0.00 & 373.78 & -464.44 & 800.00 \\
$W T A_{d,-s}$ & $206.36^{* * *}$ & 277.68 & 102.67 & 0.00 & 400.00 & -568.00 & 800.00 \\
$W T A_{-d, s}$ & $215.08^{* * *}$ & 267.57 & 100.67 & 0.00 & 352.00 & -254.67 & 800.00 \\
$W T A_{-d,-s}$ & $243.08^{* * *}$ & 305.54 & 200.00 & 0.00 & 420.00 & -800.00 & 800.00 \\
\hline$W T A^{\text {Distance }}$ & $36.72^{* *}$ & 193.56 & 0.00 & 0.00 & 31.33 & -1600.00 & 548.00 \\
$W T A^{\text {Status }}$ & $71.19^{* * *}$ & 237.29 & 0.00 & 0.00 & 114.00 & -1600.00 & 845.33 \\
\hline \hline
\end{tabular}

Notes: $W T A \mathrm{~s}$ measured in Cents. $\overline{W T A}$ is the average stated minimal difference in monetary payoffs between one's own group and all three other groups for which a group re-assignment would be accepted. $W T A_{d,-s}$ is the stated difference in monetary payoffs between one's own group and the group from the same football club and other math performance for which re-assignment to that group would be accepted. $W T A_{-d, s}$ is the stated difference in monetary payoffs between one's own group and the group from the other football club and the same math performance for which re-assignment to that group would be accepted. $W T A_{-d,-s}$ is the stated difference in monetary payoffs between one's own group and the group from the other football club and other math performance for which re-assignment to that group would be accepted. WT $A^{\text {Distance }}$ measures the difference in the stated willingness-to-accept between the group of the other status from the other football club and the group of the other status from the same football club, i.e. $W T A^{\text {Distance }}=W T A_{-d,-s}-W T A_{d,-s}$. WT $A^{\text {Status }}$ measures the difference in the stated willingness-to-accept between the group of low performance from the other football club and the group of high performance from the other football club, i.e. $W T A^{\text {Status }}=W T A_{-d, \text { low math performance }}-$ $W T A_{-d, \text { high math performance. }}$

* Significant at the 10 percent level (t-test),

** significant at the 5 percent level,

*** significant at the 1 percent level. 
Table 2: Identification and Discrimination in Allocation Decisions against Outgroups

\begin{tabular}{|c|c|c|c|}
\hline & \multicolumn{2}{|c|}{$\begin{array}{l}\text { Ingroup-Outgroup } \\
\text { Discrimination }\end{array}$} & $\begin{array}{c}\text { Outgroup-Outgroup } \\
\text { Discrimination } \\
(3)\end{array}$ \\
\hline \multicolumn{4}{|c|}{ Identification Preference } \\
\hline Dummy & $\begin{array}{c}0.191^{*} \\
(0.099)\end{array}$ & & $\begin{array}{l}0.368^{* * *} \\
(0.101)\end{array}$ \\
\hline Continuous & & $\begin{array}{c}0.013 \\
(0.021)\end{array}$ & \\
\hline Age & $\begin{array}{c}0.010 \\
(0.010)\end{array}$ & $\begin{array}{c}0.011 \\
(0.010)\end{array}$ & $\begin{array}{c}0.003 \\
(0.007)\end{array}$ \\
\hline Male & $\begin{array}{c}0.014 \\
(0.089)\end{array}$ & $\begin{array}{c}0.047 \\
(0.079)\end{array}$ & $\begin{array}{c}0.043 \\
(0.100)\end{array}$ \\
\hline Undergrad & $\begin{array}{c}-0.068 \\
(0.110)\end{array}$ & $\begin{array}{c}-0.051 \\
(0.108)\end{array}$ & $\begin{array}{c}-0.211 \\
(0.106)\end{array}$ \\
\hline Observations & 128 & 128 & 128 \\
\hline Pseudo $R^{2}$ & 0.037 & 0.016 & 0.117 \\
\hline
\end{tabular}

Notes: Average marginal effects of logistic regressions with clustered standard errors at the group level in parentheses. The dependent variable is discrimination between different groups in the dictator game. In columns (1) and (2), the dependent variable is equal to 1 if members of at least one of the three outgroups were given a lower payoff than members of the own group, and 0 otherwise. In column (3), the dependent variable is equal to 1 if members of the three outgroups received different payoffs, and 0 otherwise. In column (1), the Identification Preference Dummy is 1 if the average willingness-to-accept over all three outgroups exceeds the median, and 0 otherwise. In column (2), we use the average stated willingness-to-accept measured in Euros over all three outgroups as the continuous measure of Identification Preferences. In column (3), the Identification Preference Dummy is equal to 1 if the willingness-to-accept varies across the three outgroups and 0 otherwise. Age is measured in years, male is a dummy variable which is equal to 1 for men, and undergrad is equal to 1 for bachelor students, and 0 otherwise.

* Significant at the 10 percent level,

** significant at the 5 percent level,

*** significant at the 1 percent level. 
Table 3: Identification and Discrimination in Allocation Decisions across Outgroups

\begin{tabular}{|c|c|c|c|c|}
\hline & \multicolumn{4}{|c|}{ Outgroup Discrimination in Allocation Decisions } \\
\hline & \multicolumn{2}{|c|}{ Ingroup-Outgroup } & \multicolumn{2}{|c|}{ Outgroup-Outgroup } \\
\hline & No Controls & $\begin{array}{c}\text { Outgroup } \\
\text { characteristics }\end{array}$ & No Controls & Controls \\
\hline & $(1)$ & $(2)$ & $(3)$ & $(4)$ \\
\hline Identification Preference & $\begin{array}{c}-0.128^{* * *} \\
(0.034)\end{array}$ & $\begin{array}{c}-0.080^{* *} \\
(0.034)\end{array}$ & $\begin{array}{c}-0.104^{* * *} \\
(0.037)\end{array}$ & $\begin{array}{c}-0.101^{* * *} \\
(0.036)\end{array}$ \\
\hline $\begin{array}{l}\text { Outgroup } \\
\text { - Other Club }\end{array}$ & & $\begin{array}{c}-0.601^{* * *} \\
(0.132)\end{array}$ & & \\
\hline Outgroup & & $0.157^{*}$ & & \\
\hline - Low Performance & & $(0.084)$ & & \\
\hline Fixed Effects & Yes & Yes & No & No \\
\hline Controls & No & No & No & Yes \\
\hline Observations & 512 & 512 & 384 & 384 \\
\hline$R^{2}$ & 0.052 & 0.135 & 0.027 & 0.064 \\
\hline
\end{tabular}

Notes: Coefficient estimates of fixed-effects (columns 1 and 2) and pooled OLS (columns 3 and 4) regressions with clustered standard errors at the individual level in parentheses. In columns (1) \& (2), the dependent variable is the amount given to the recipient in the dictator game for each of the four groups (measured in Euros). In columns (3) $\&(4)$, the dependent variable is equal to the difference in the amounts given to the recipient in the dictator game for a given outgroup pair (measured in Euros). Identification Preference is measured as the stated WTA for the particular outgroup in Euros in columns (1) \& (2). In columns (3) \& (4), Identification Preference is measured as the difference in $W T A$ s between the respective outgroups. Outgroup - Other Club is equal to 1 if the outgroup is from the other football club, and 0 otherwise. Outgroup - Low Performance is equal to 1 if the outgroup had a low performance in the math task, and 0 otherwise. Controls include age, gender, and undergrad. Age is measured in years, gender is equal to 1 for men, and undergrad is equal to 1 for bachelor students, and 0 otherwise. For the fixed-effects regressions (columns $1 \& 2$ ), $R^{2}$ reports within- $R^{2}$ values.

* Significant at the 10 percent level,

** significant at the 5 percent level,

*** significant at the 1 percent level. 
Table 4: Comparison of the Experimental Designs

\begin{tabular}{lcc}
\hline \hline & Pilot Study & Main Experiment \\
\hline Laboratories & Frankfurt \& Trier & Frankfurt \& Cologne \\
Participants & 192 & 128 \\
Stage 1: Group Assignment & & \\
Social Distance & University & Football Club \\
Social Status & Performance Math Task \\
Stage 3: $W T$ A Elicitation & & \\
Elicitation Procedure & Text Box & Scrollbar \\
Control Questions & Examples & Optimal Strategies \\
Stage 4: Allocation Decisions & 4 Binary Dictator Games & 1 Continuous Dictator Game \\
Stage 5: No Payoff Consequences & Implicit & Explicit \\
\hline
\end{tabular}




\section{Figures}

\section{Stage}

1

2

34

5

6

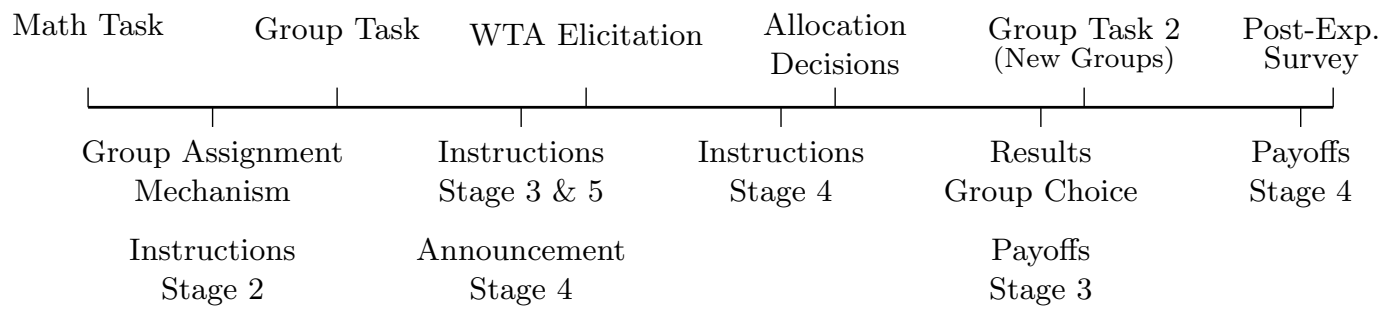

\section{Information}

Figure 1: Timeline of the Experiment 


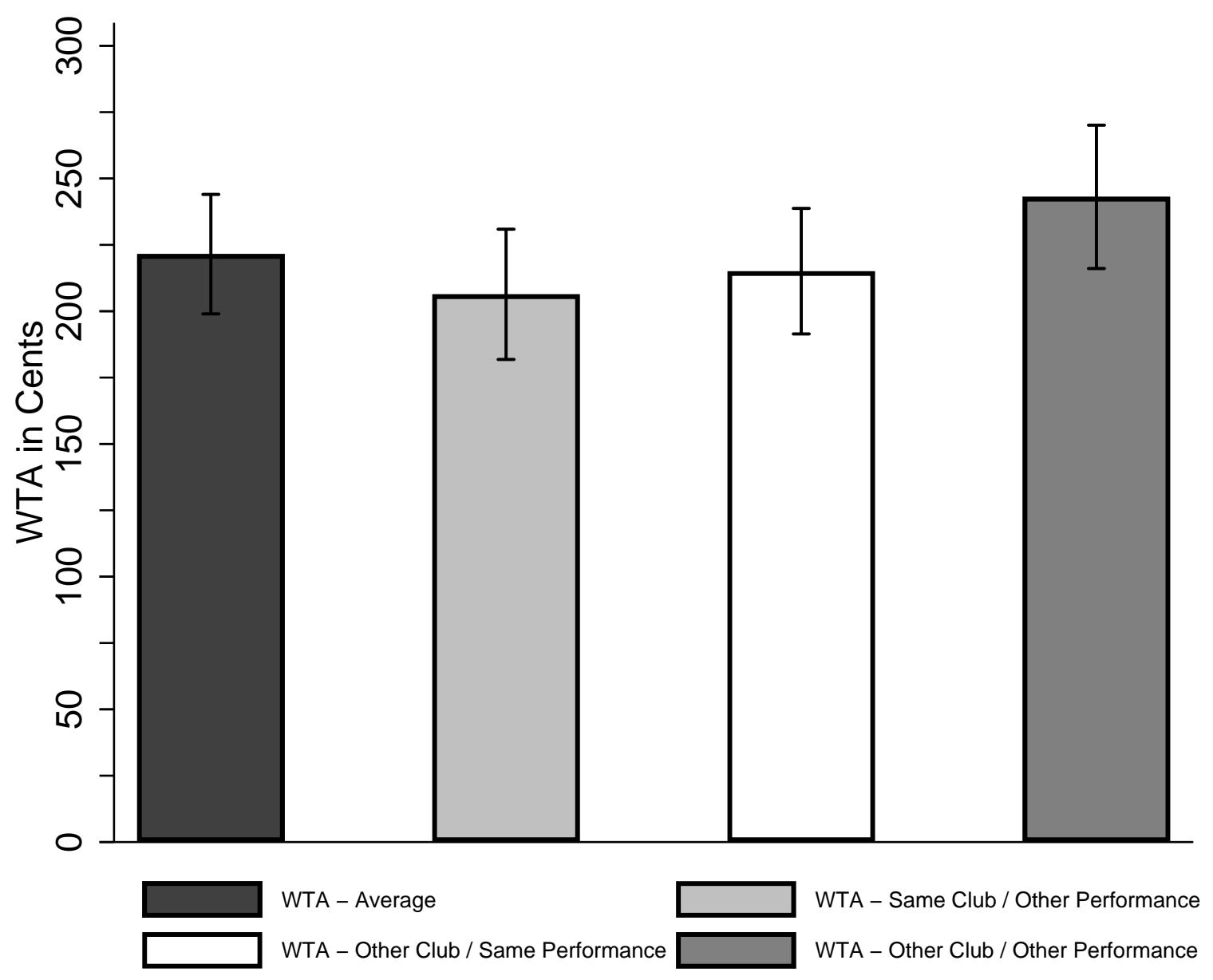

Figure 2: Identification Preferences

Notes: The vertical axis indicates the $W T A$ in Cents, the bars depict the average $W T A \pm \mathrm{SE}$ over all groups (dark grey bar) and over the three different outgroups. 


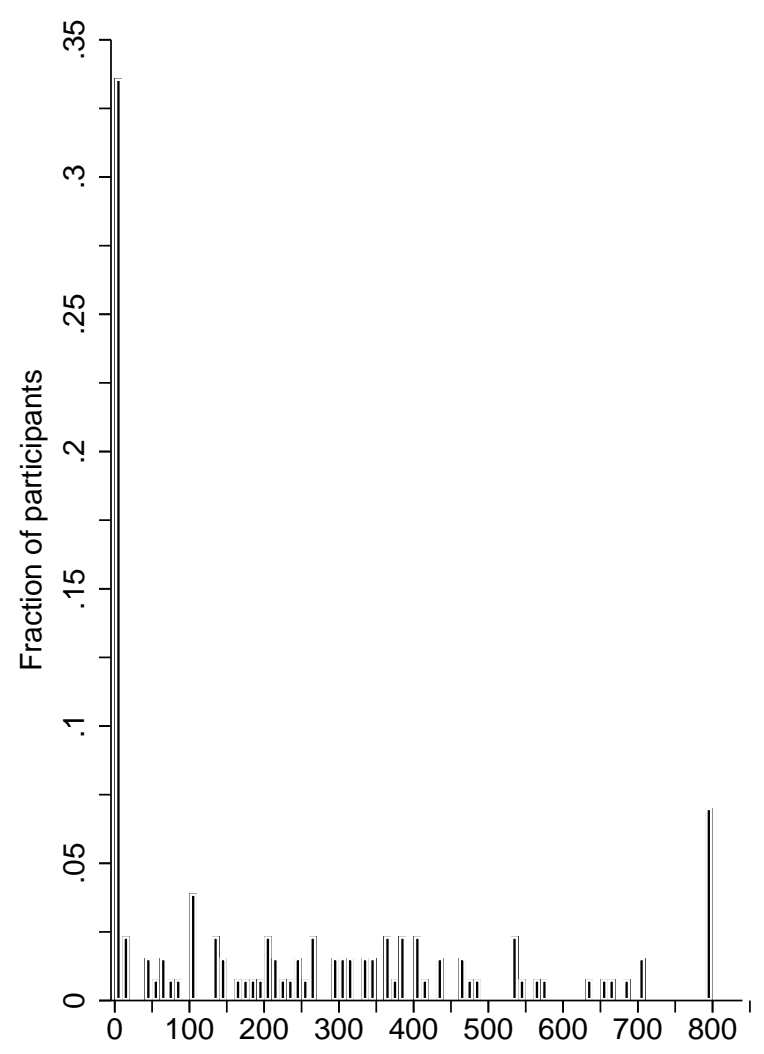

(a) Average WTA

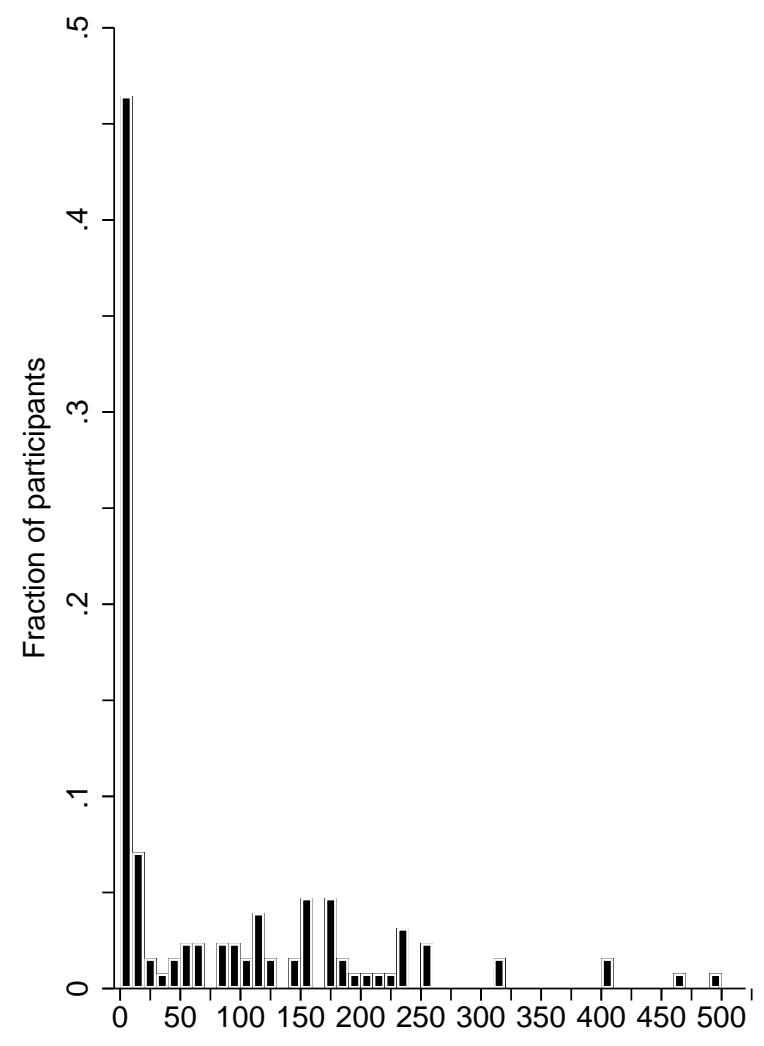

(b) Standard Deviation in WTA

Figure 3: WTA: Average and Standard Deviation

Notes: Panel (a) presents the histogram of participants' average WTA over the three outgroups, panel (b) shows the histogram of the within-participant $W T A$ standard deviation across outgroups. 


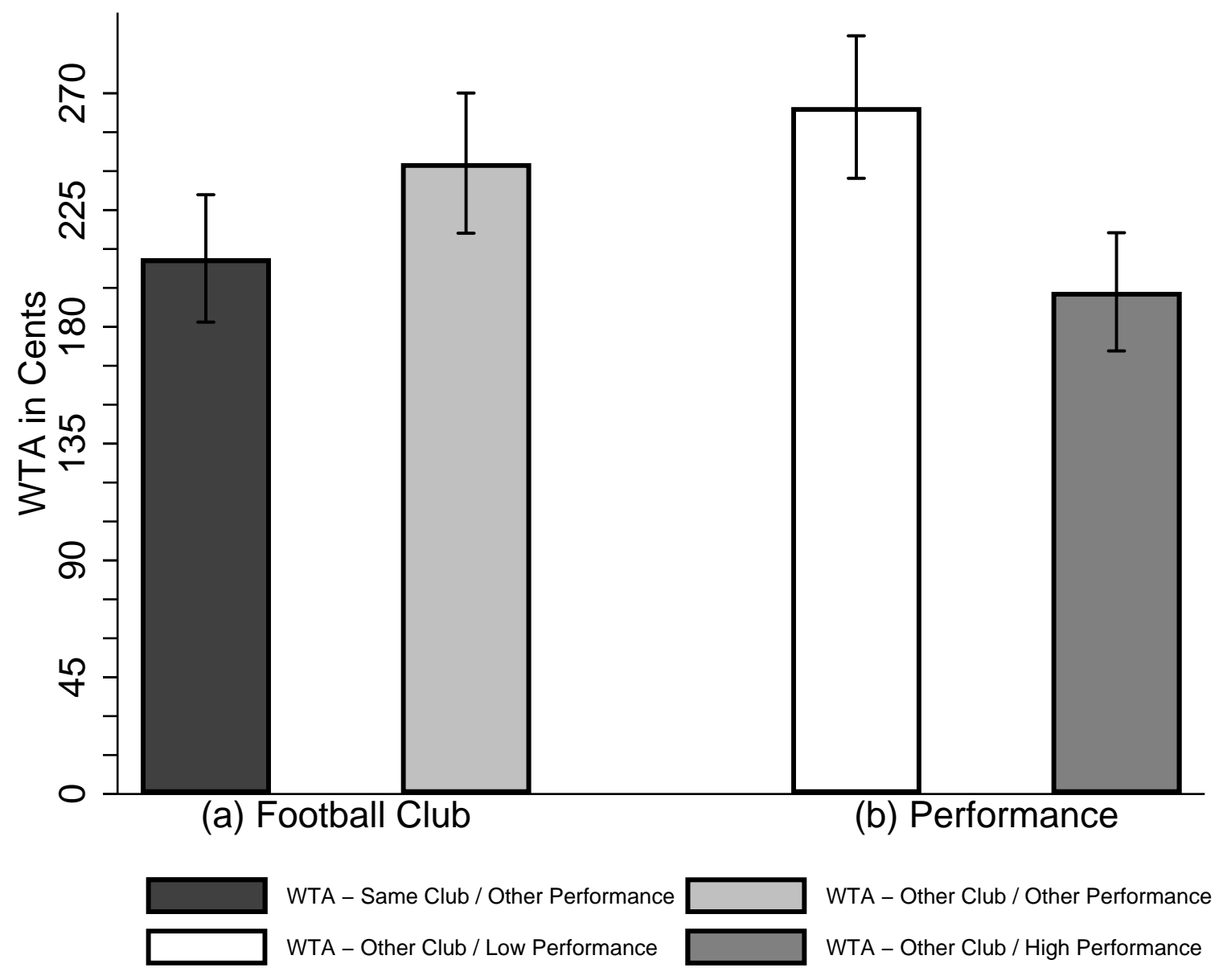

Figure 4: Identification Preferences: Social Distance and Social Status

Notes: The vertical axis indicates the WTA in Cents. The bars in panel (a) represent the social distance dimension (by varying outgroup football club affiliation and holding outgroup performance constant) \pm SEs, the bars in panel (b) represent the social status dimension (by varying outgroup performance and holding outgroup football club affiliation constant) \pm SEs. 


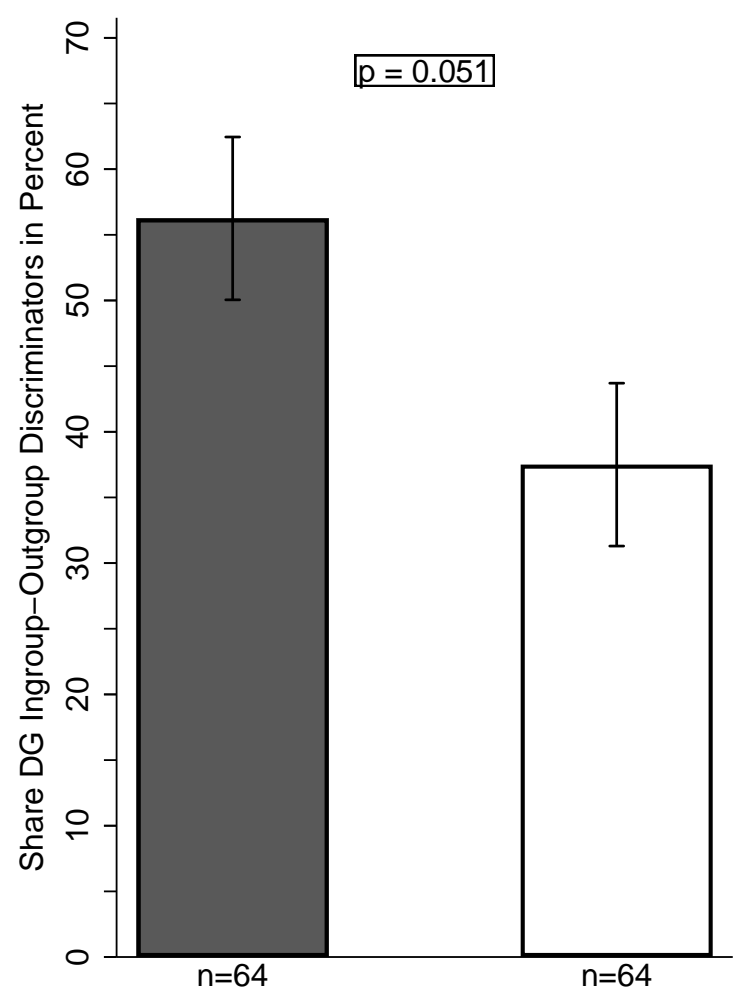

(a)

WTA High

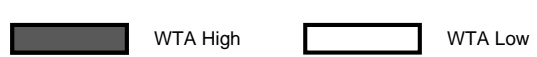

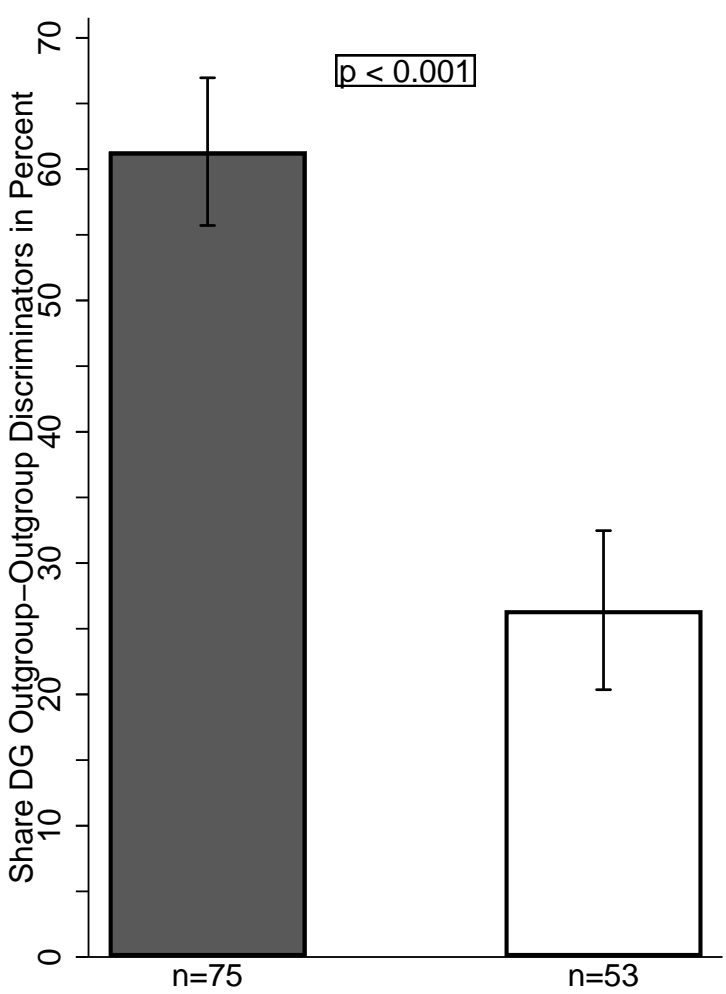

(b)

Figure 5: Discrimination in Allocation Decisions: the Role of Identification Preferences

Notes: In Panel (a), the vertical axis indicates the share of participants who discriminate between the own group and any of the three outgroups in the dictator game. The sample is split by participants' average WTA (grey bar: above median, white bar: below median). In Panel (b), the vertical axis indicates the share of participants who discriminate across the three outgroups in the dictator game. The grey bar represents the participants who discriminate between outgroups with respect to their $W T A$, while the white bar represents those whose $W T A$ does not differ between outgroups. All bars \pm SE. $p$-values from two-sided Fisher's exact tests. 


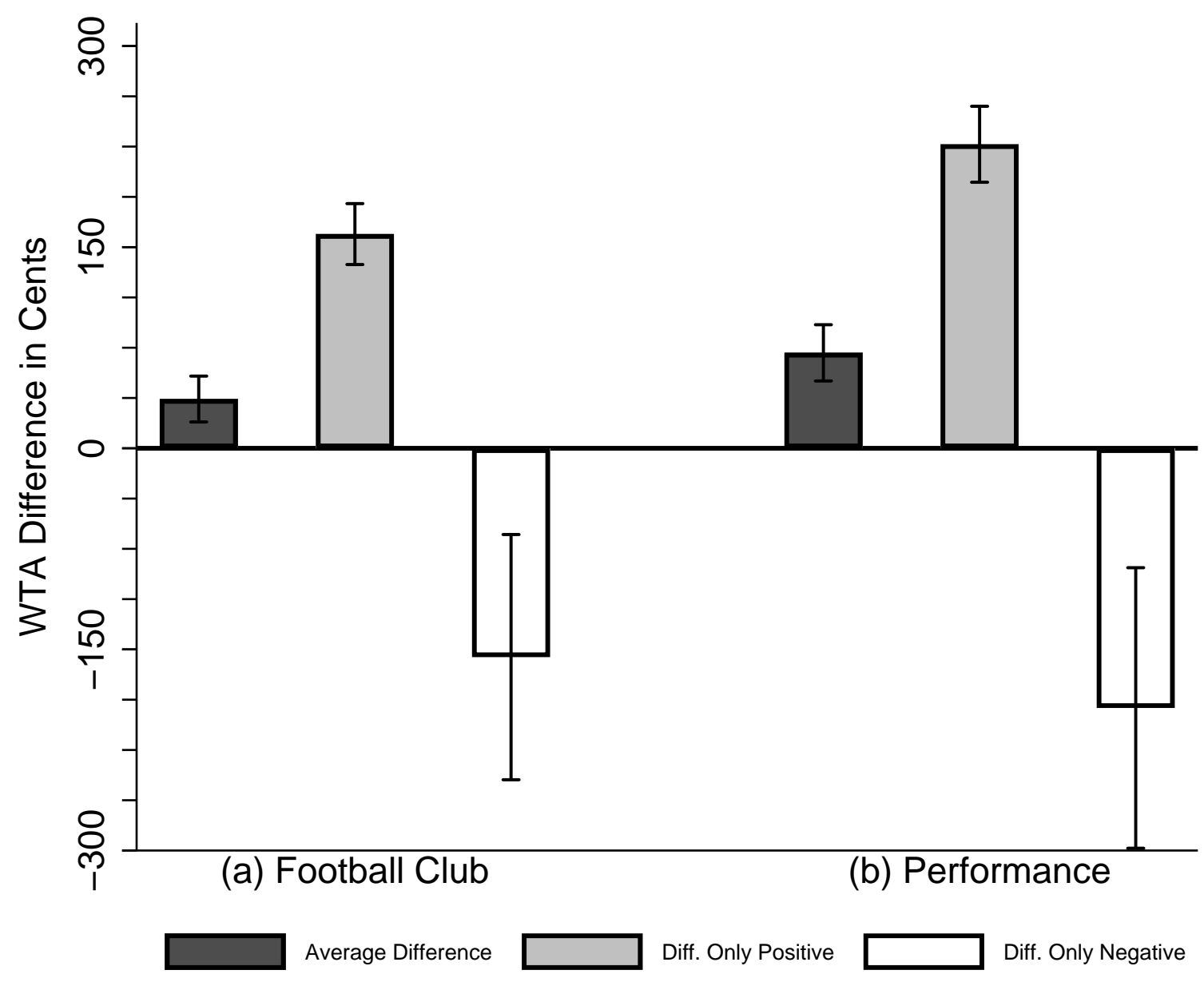

Figure 6: Identification Preferences: Heterogeneity

Notes: The vertical axis indicates the WTA difference in Cents in (a) the football club dimension and (b) the performance dimension. The light grey (white) bars show the averages for the subsamples of participants with positive (negative) WTA differences \pm SE. The dark grey bars refer to the full sample \pm SE. 


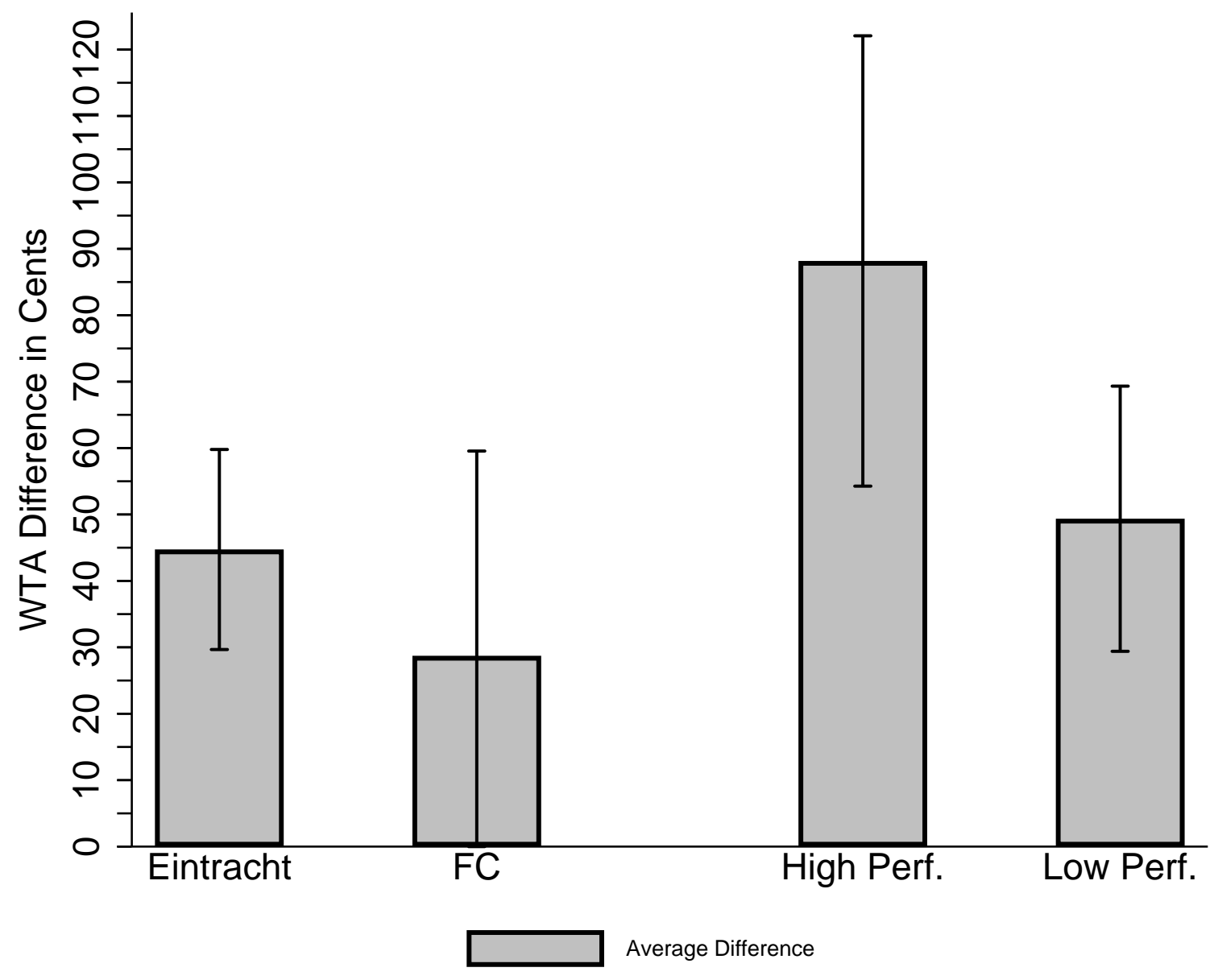

Figure 7: Identification Preferences: Heterogeneity in Social Distance and Social Status

Notes: The vertical axis indicates the WTA difference in Cents. Samples are split by football clubs (first two bars) and by math performance (bars three and four). The first two bars represent $W T A^{\text {Distance }} \pm$ SEs for the two football club subsamples, while the last two bars report $W T A^{\text {Status }} \pm$ SEs for the high and low performance groups. 


\title{
For Online Publication
}

\author{
ONLINE APPENDIX: \\ Choosing Who You Are: The Structure and \\ Behavioral Effects of Revealed Identification Preferences
}

Florian Hett, Markus Kröll, and Mario Mechtel

\section{Appendix A. Additional Results}

\section{Heterogeneity in Identification Preferences}

In this section, we give a more detailed account of the role of social distance and social status for identification preferences. As outlined in Section 3.1, both of these components affect identification preferences. Individuals identify more strongly with groups of close social distance and higher social status. As previously discussed, while social distance appears to have a weaker impact than social status, heterogeneity in the individuals' responses to social distance conceals its strength in the aggregate analysis. It is not just that a large share of individuals (65 out of the 128) do not distinguish between the two respective outgroups, but also that 17 participants identify more strongly with the group of the other club. For these individuals, WT $A^{\text {Distance amounts to }-155.76}$ Cents (or 38.9 percent of expected earnings) and thus considerably pulls down the aggregate value for the full sample (see panel (a) of Figure 6).

The choices of these 17 participants seem puzzling at first glance, because they appear to identify more strongly with the group to which they have a higher social distance. However, data from our post-experimental questionnaire hints at another explanation. Asked to rate the relative reputation of the other club compared to one's own club, the vast majority of participants ( $\sim 79$ percent) perceive the two clubs to be about equal. For the 17 participants who identify more strongly with the other club, the perception of their own club is significantly lower than for the other participants ( $p=0.0219$ in a two-sided t-test). This indicates that their decision might be driven by social status concerns, which could manifest themselves in the club affiliation as well.

As for social distance, we also observe substantial heterogeneity between individuals with respect to social status (see panel (b) of Figure 6). 53.1 percent of the participants display status-induced differences in identification (i.e. state different $W T A$ s for the two groups from the other club). Out of these, 53 participants (or 41.4 percent of the full sample) identify more strongly with the high status group, i.e. WT $A^{\text {Status }}>0$. Their average stated difference is 226.74 Cents (grey bar), which equates to 56.7 percent of expected earnings, underlining the importance of social status for 
identification. Another 15 individuals, however, show a somewhat lower yet still strong identification with the low status group (white bar) and request 193.69 Cents more to accept re-assignment to the high status group.

This heterogeneity is due to an asymmetry in the effect of status. Breaking down identification preferences regarding status for participants of high and low status groups indeed reveals an interesting pattern (Figure 7). The overall status effect is driven by participants from the high status groups. While participants from the high status groups strongly and almost exclusively identify with the high status group, there is a less clear pattern for members of the low status groups. Only $8.33 \%$ of the participants from high status groups identify with low status groups (and 55.55\% with high status groups). In contrast, among those from low status groups, $16.1 \%$ identify with low status groups (and only 37.5\% with high status groups).

This result demonstrates that social distance and social status are inherently intertwined, as participants might perceive social distance not only with respect to football club affiliation, but also with respect to status. Any variation in the status dimension automatically also induces differences in the social distance dimension, as differences in the characteristic that induces status imply a social distance in this characteristic as well. For individuals from a high status group, a high status group from the other club dominates a low status group from the other club in both, social status and social distance. For individuals from a low status group, however, the high status group from the other club provides higher social status, but also larger social distance.

Alternatively, the social identity literature suggests that individuals might devalue dimensions in which their ingroup performs poorly and focus on other dimensions instead (Turner and Brown 1978, Tajfel and Turner 1979, Hogg and Abrams 1988, Hornsey 2008). Consistent with that idea is Wichardt's (2008) argument that individuals who are confronted with different dimensions of group characteristics focus the more on a particular group the more it offers them a positive contribution to their identity in a certain context. Akerlof (2017) focuses on a similar margin along which individuals can manage identity: reweighting "achievements" in different dimensions. Our result that WTA differences in the status dimension are much stronger for members of high status groups corroborates this hypothesis. It is consistent with the notion that participants from the low status groups endogenously put less weight on the status dimension than participants from the high status groups. For future research, it would thus be worthwhile to investigate in more detail the effect of a group's relative performance in different dimensions of social identity on the role these dimensions actually play in identification choices. 


\section{Appendix B. Pilot Study}

\section{Experimental Design}

Our pilot study consisted of the same five stages as the main experiment. We assigned groups based on two characteristics in the first stage and used three unincentivized picture puzzles and a chat phase for group enhancement through joint activity. We then used the same revealed preference approach to elicit identification preferences in stage 3 and measured identity-contingent social preferences with a simple dictator game in stage 4 . The experiment was also capped with a second unincentivized round of picture puzzles after payoff-realizations as well as group changes were revealed. While the pilot thus fully matches the main experiment in terms of the underlying experimental strategy and design, there are some important procedural differences which have in parts already been discussed in Section 3.3 and which we will elaborate on in more detail here.

Group Assignment Characteristics - Even though our main experiment was successful in spanning an identity space which reflected social distance and social status, there exist other categories than football club affiliation which potentially also carry social distance. In the pilot, we used university affiliation instead of the favorite football club for the social distance dimension. Participants' affiliation with one of two different public universities served as a first assignment rule to different groups. Identification with one's alma mater is less salient in Germany than for example the US, where university affiliation is more culturally ingrained and reinforced by intercollegiate competition 23 We therefore expected the role of social distance to be less pronounced than we later did in the main experiment.

We conducted the pilot simultaneously at two universities. Participants were part of the subject pools of the Frankfurt Laboratory for Experimental Economic Research (FLEX) and the Trier Laboratory for Experimental Economics (TREX). For the social status dimension, we used the same math task as in the main experiment and assigned participants in high or low performance groups contingent on their performance in this task.

Elication Procedure and Experimental Currency - In the pilot study, we did not use Euros as currency, but experimental points. At stage 3, each of the four groups was attached a random point value $\pi_{d, s}, d \in\{$ University A, University B,$s \in\{$ high performance, low performance $\}$, drawn from a uniform distribution in the interval [200,800]. Participants were paid 1 Euro per 100 points earned in the experiment. Contrary to the sliders used in the main experiment, we used plain text boxes to elicit the $W T A$ s in our pilot study.

One might fear that the plain text boxes could artificially inflate the $W T A$ s because participants might have felt compelled to add a positive number. Additionally, although the experimental set-

\footnotetext{
${ }^{23}$ Note that the overwhelming majority of participants perceive the reputation of the two universities to be about equal. This suggests that there is no status difference between universities.
} 
ting was very transparent, participants might not have been aware that entering negative values was viable. Indeed, we found that only a very small fraction of participants stated WTAs of 0 and did not care about group affiliation $(<8 \%)$. Nobody entered a negative number. In the main experiment, we therefore replaced the text boxes with the scrollbars ranging from -8 Euro to +8 Euro. This highlighted the possibility that stating a negative $W T A$ (i.e. expressing to prefer another group to the initial one even if this group's payoff is lower) was possible and allowed us to specify a default, which we set at 0 . The pilot study is, thus, an interesting setting to test for the robustness of our findings when varying an important design feature.

Dictator Games - The main experiment makes use of a continuous dictator game with an efficiency component. The efficiency loss which is inevitably attached to ingroup bias in these allocation choices might reduce the average level of ingroup favoritism. Our measure in the main experiment might, thus, be interpreted as a rather conservative one. A continuous dictator game with a multiplier to generate the efficiency effects (see Section 2.2) complicates decision-making compared to a standard dictator game. In the pilot study, we limited participants' actions to binary decisions. Participants took part in four two-person dictator games selected from Bartling et al. (2009) to elicit group-specific social preferences (see Table B.1. As in the main experiment, we used the strategy-method to collect decisions for all groups. Every individual had to choose an allocation between herself and another member of each of the three other groups as well as between herself and a member of her own group.

Table B.1: Allocation Games used in the Pilot Study

\begin{tabular}{|c|c|}
\hline Game & Choice \\
\hline Prosocial & $(400,400)$ vs. $(400,240)$ \\
\hline Costly Prosocial & $(400,400)$ vs. $(640,160)$ \\
\hline Envy & $(400,400)$ vs. $(400,720)$ \\
\hline Costly Envy & $(400,400)$ vs. $(440,760)$ \\
\hline
\end{tabular}

The main findings are the same in the pilot study and the main experiment. The binary dictator games, however, potentially cloud heterogeneity in discrimination behavior for those participants who would like to discriminate at an intermediate level between the two binary options. We therefore chose to use the continuous dictator games in the main experiment. 
Instructions and Control Questions - We altered the control questions in the main experiment in order to make the payoffs in the third stage even more salient and ensure that all participants understood the payoff consequences of their decisions. In the pilot study, we provided the participants with examples and asked them what would happen under the described circumstances. In the main experiment, we opted for comprehension questions which focused on the optimal strategy given a certain objective. More specifically, every individual had to state the optimal strategy for three types of individuals: (i) an individual who would like to remain with her initial group, (ii) one who would like to leave her initial group, and (iii) one who does not care about group membership and wants to maximize her own payoffs.

Additionally, we rephrased the description of the second round of picture puzzles and group chats in the main experiment. In the pilot, we stated that this second phase would be fully identical to the first one aside from the potential new group compositions. This implies that this stage has no payoff consequences. However, one might argue that participants still had some strategic considerations when making their identification choices. We therefore added the following line to the instructions of stage 3 in the main experiment: "As in the previous round, you will not be paid for a correct answer."

\section{Results}

We ran the pilot study with 192 participants. Table 4 provides an overview of the key features and differences to the main experiment as described above. Within this section, we describe the results of the pilot in detail and relate them to our findings presented in the main part of the paper.

Participants' average WTA amounts to 182.22 points in the pilot study, which equals $36.44 \%$ of expected earnings at the group selection stage (see Table B.2 and Figure B.1). The WTA average over all participants is significantly different from 0 (t-test: $p<0.0001$ ). The same holds for the average values of outgroup-specific WTAs. The highest average $W T A$ (201.24 points) results for the outgroup of different performance and the other university, while average $W T A$ is the lowest for the outgroup of the same performance and the other university (159.30 points). This latter finding is a first indicator for a less important role of the social distance (i.e. university) dimension in the pilot study. While the absolute value of average $W T A$ in the main experiment is higher than in our pilot study, we should take into account that a group's potential $W T A$ ranges between 0 and 8 Euros in the main experiment instead of 0 and 600 points in the pilot. In contrast to the main experiment, no participant states a negative $W T A$ average for all three outgroups (2 participants in the main experiment). The share of participants for whom groups do not matter is larger in the main experiment (26.6\% with an average $W T A$ of 0$)$ than in the pilot, where only 15 of 192 participants choose a WTA average of 0 or 1.26 percent of the participants even state $W T A \mathrm{~s}$ larger than 250, which corresponds to 50 percent of expected earnings from the group selection 
stage in the pilot study. Combining these results supports the findings that groups matter and that there is much heterogeneity with respect to the perceived importance of groups. Taken together, Result 1 is, thus, confirmed by the pilot study.

Result 2 focuses on the structure of identification preferences (see Figure B.3). As in the main experiment, we compare the $W T A$ regarding two outgroups of the same math performance but different universities to identify the role of social distance. On average, the $W T A$ difference amounts to 15.4 points and is statistically significant (two-sided t-test: $p<0.005$ ). The first part of Result 2 is, thus, confirmed. The same holds true for the second part: social status matters for identification. On average, participants have a 48.2 points higher $W T A$ regarding the outgroup from the other university that performed worse in the math task. While the social distance effect amounts to around $32 \%$ of the social status effect in the pilot study, its relative importance is substantially higher in the main experiment (roughly 52\%).

Results 3 and 4 establish that identification preferences are related to ingroup-outgroup discrimination and outgroup-outgroup discrimination. The data from the pilot study confirm that participants who identify more strongly with their initial group are significantly more likely to discriminate against outgroups. This is true both for the replication of Figure 5 (see Figure B.4) and a logistic regression where the explanatory variable of main interest is a dummy that equals 1 if a participant's average WTA exceeds the median value (column (1) of Table B.3). The average marginal effect equals 0.16 and is, thus, very similar to that in column (1) of Table 2. Applying a participant's WTA average as continuous measure for identification preferences yields a positive and also statistically significant marginal effect in the pilot study (column (2) of Table B.3). The probability of discrimination against at least one outgroup in the allocation games rises by 7.2 percentage points for every 100 point increase in the average $W T A$.

This relation holds not only at the aggregate level but also for specific outgroups. In the flavor of Table 3. Table B.4 presents results of a logistic regression considering discrimination against a particular outgroup $k$ in at least one of the four dictator games as the dependent variable. Our explanatory variable of main interest captures identification with the receiver's group. It equals the outgroup-specific $W T A$. As the binary version of the dictator games utilized in the pilot study does not allow for the inclusion of participant fixed effects, we add control variables available at the individual level. The estimations strongly support the results from Table 3 the stronger the level of identification with the receiver's group, the larger is the amount sent by a participant. This result is independent of whether we control for outgroup characteristics (i.e. other university and low performance) or not and whether we additionally include individual control variables or not. Result 3 is, thus, supported by the pilot study.

Our finding that WTA discrimination across outgroups relates to discrimination in allocation choices across outgroups (Result 4) is also supported by the pilot study. As can be seen from 
Figure B.4, the share of outgroup-outgroup allocation discriminators is significantly larger among those participants who also discriminate across two particular outgroups with respect to $W T A$ in the flavour of Figure 5. This result also holds for the pilot study when introducing additional controls (as in column (3) of Table B.3). The marginal effect of the WTA dummy which captures a $W T A$ difference between outgroups is 0.430 and statistically significant at the $1 \%$-level. Furthermore, the result is confirmed when focusing on the group-level (as in columns (4) and (5) of Table B.4.).

Overall, the pilot study supports the results from our main experiment. We find that identification preferences matter in general (Result 1), and in particular with respect to a group's social distance and social status (Result 2), and that identification preferences predict group specific social preferences (Results 3 and 4). As expected, the role of social distance was smaller when referring to universities rather than football clubs. 


\section{Tables and Figures}

Table B.2: Summary Statistics - Identification Preferences - Pilot Study

\begin{tabular}{lcrrrrrc}
\hline \hline & Mean & $\begin{array}{r}\text { Std. } \\
\text { Dev. }\end{array}$ & Median & $\begin{array}{r}\text { Lower } \\
\text { Quart. }\end{array}$ & $\begin{array}{r}\text { Upper } \\
\text { Quart. }\end{array}$ & Min & Max \\
\hline$\overline{W T A}$ & $182.22^{* * *}$ & 128.85 & 175.00 & 86.67 & 263.33 & 0.00 & 600.00 \\
$W T A_{d,-s}$ & $186.11^{* * *}$ & 141.25 & 200.00 & 100.00 & 280.00 & 0.00 & 600.00 \\
$W T A_{-d, s}$ & $159.30^{* * *}$ & 133.77 & 150.00 & 50.00 & 200.00 & 0.00 & 600.00 \\
$W T A_{-d,-s}$ & $201.24^{* * *}$ & 149.29 & 200.00 & 100.00 & 300.00 & 0.00 & 600.00 \\
\hline$W T A^{\text {Distance }}$ & $15.14^{* * *}$ & 64.03 & 0.00 & 12.50 & 0.00 & -211.00 & 300.00 \\
$W T A^{\text {Status }}$ & $48.20^{* * *}$ & 116.73 & 0.00 & 0.00 & 100.00 & -200.00 & 600.00 \\
\hline \hline
\end{tabular}

Notes: $W T A$ is measured in experimental points. $\overline{W T A}$ is the average stated minimal difference in monetary payoffs between one's own group and all three other groups for which a group re-assignment would be accepted. $W T A_{d,-s}$ is the stated difference in monetary payoffs between one's own group and the group from the same university and other math performance for which re-assignment to that group would be accepted. $W T A_{-d, s}$ is the stated difference in monetary payoffs between one's own group and the group from the other university and the same math performance for which re-assignment to that group would be accepted. $W T A_{-d,-s}$ is the stated difference in monetary payoffs between one's own group and the group from the other university and other math performance for which re-assignment to that group would be accepted. WT $A^{\text {Distance }}$ measures the difference in the stated willingness-to accept between the group of the other status from the other university and the group of the other status from the same university, i.e. $W T A^{\text {Distance }}=W T A_{-d,-s}-W T A_{d,-s} . W T A^{\text {Status }}$ measures the difference in the stated willingness-to accept between the group of low performance from the other university and the group of high performance from the other university, i.e. $W T A^{\text {Status }}=W T A_{-d \text {,low math performance }}-$ $W T A_{-d \text {,high math performance. }}$

* Significant at the 10 percent level (t-test),

** significant at the 5 percent level,

*** significant at the 1 percent level. 
Table B.3: Identification and Discrimination in Allocation Decisions against Outgroups - Pilot Study

\begin{tabular}{lccc}
\hline \hline \multirow{2}{*}{$\begin{array}{c}\text { Ingroup-Outgroup } \\
\text { Discrimination }\end{array}$} & $\begin{array}{c}\text { Outgroup-Outgroup } \\
\text { Discrimination }\end{array}$ \\
& $(1)$ & $(2)$ & $(3)$ \\
\hline Identification Preference & & & $0.430^{* * *}$ \\
Dummy & $0.160^{* *}$ & & $(0.056)$ \\
Continuous & $(0.065)$ & & \\
& & $0.072^{* *}$ & \\
Age & & $(0.029)$ & 0.009 \\
& & & $(0.007)$ \\
Male & 0.000 & 0.000 & -0.026 \\
& $(0.011)$ & $(0.012)$ & $(0.067)$ \\
Undergrad & $-0.160^{* *}$ & $-0.169^{* *}$ & -0.059 \\
& $(0.071)$ & $(0.070)$ & $(0.072)$ \\
\hline Observations & -0.013 & -0.005 & 192 \\
Pseudo $R^{2}$ & $(0.089)$ & $(0.089)$ & 0.167 \\
\hline \hline
\end{tabular}

Notes: Average marginal effects of logistic regressions with clustered standard errors at the group level in parentheses. The dependent variable is discrimination between different groups in one of the four allocation games. In columns (1) and (2), the dependent variable is equal to 1 if members of at least one of the three outgroups were given a lower payoff than members of the own group, and 0 otherwise. In column (3), the dependent variable is equal to 1 if members of the three outgroups received different payoffs, and 0 otherwise. In column (1), the Identification Preference Dummy is 1 if the average willingness-to-accept over all three outgroups exceeds the median, and 0 otherwise. In column (2), we use the average stated willingness-to-accept in units of 100 experimental points over all three outgroups as the continuous measure of Identification Preferences. In column (3), the Identification Preference Dummy is equal to 1 if the willingness-to-accept varies across the three outgroups and 0 otherwise. Age is measured in years, male is a dummy variable which is equal to 1 for men, and undergrad is equal to 1 for bachelor students, and 0 otherwise.

* Significant at the 10 percent level,

** significant at the 5 percent level,

*** significant at the 1 percent level. 


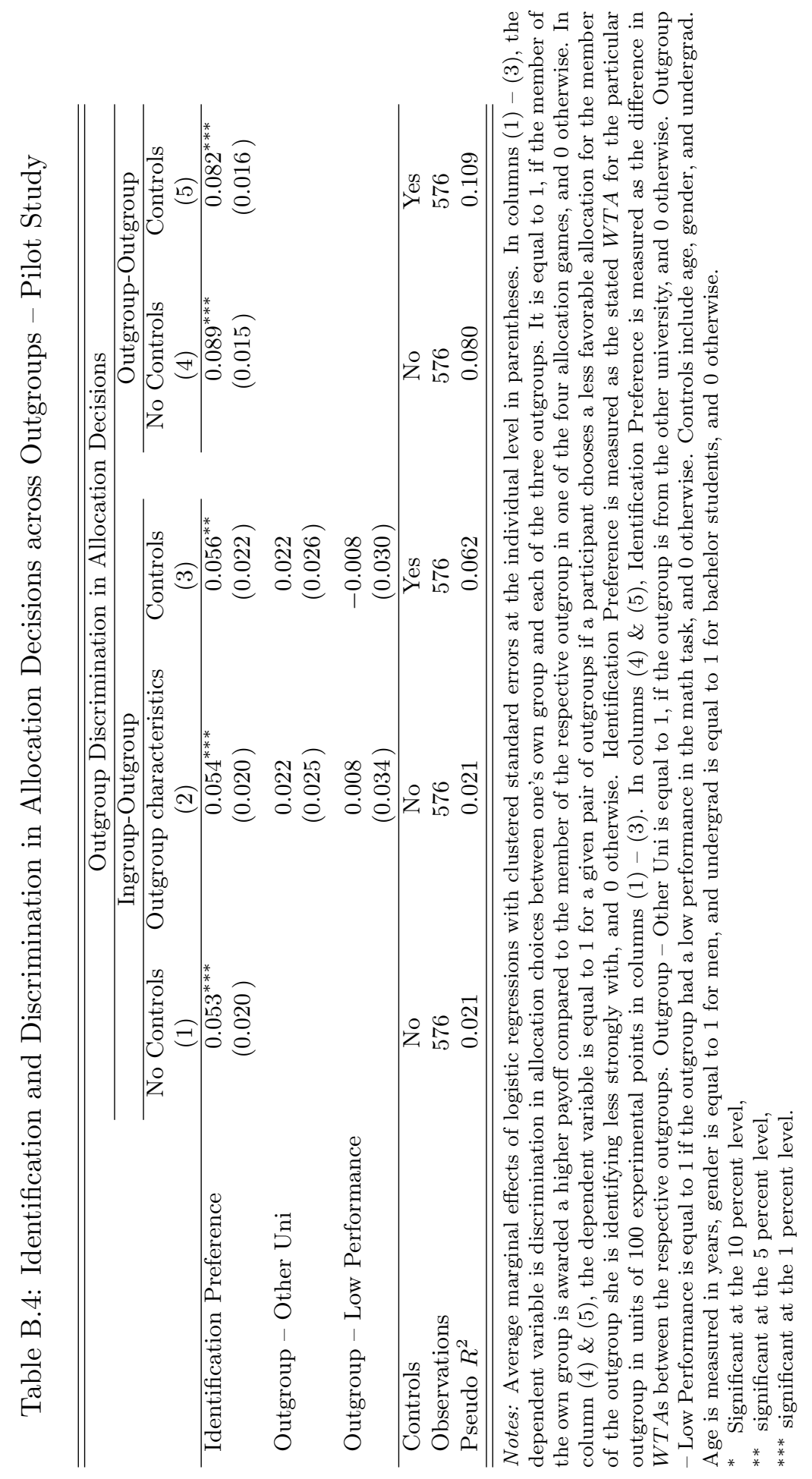




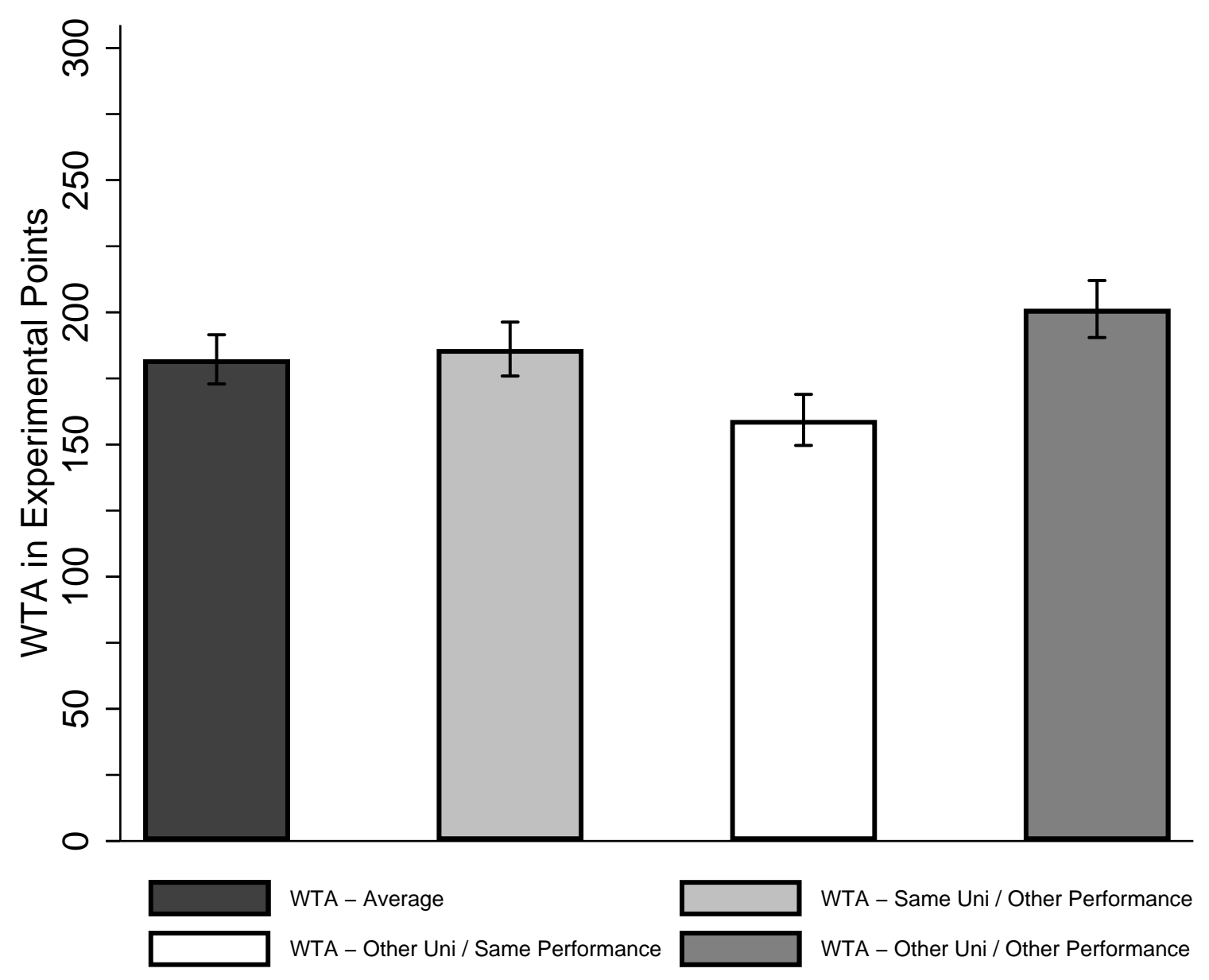

Figure B.1: Identification Preferences - Pilot Study

Notes: The vertical axis indicates the $W T A$ in experimental points, the bars depict the average $W T A \pm \mathrm{SE}$ over all groups (dark grey bar) and over the three different outgroups. 

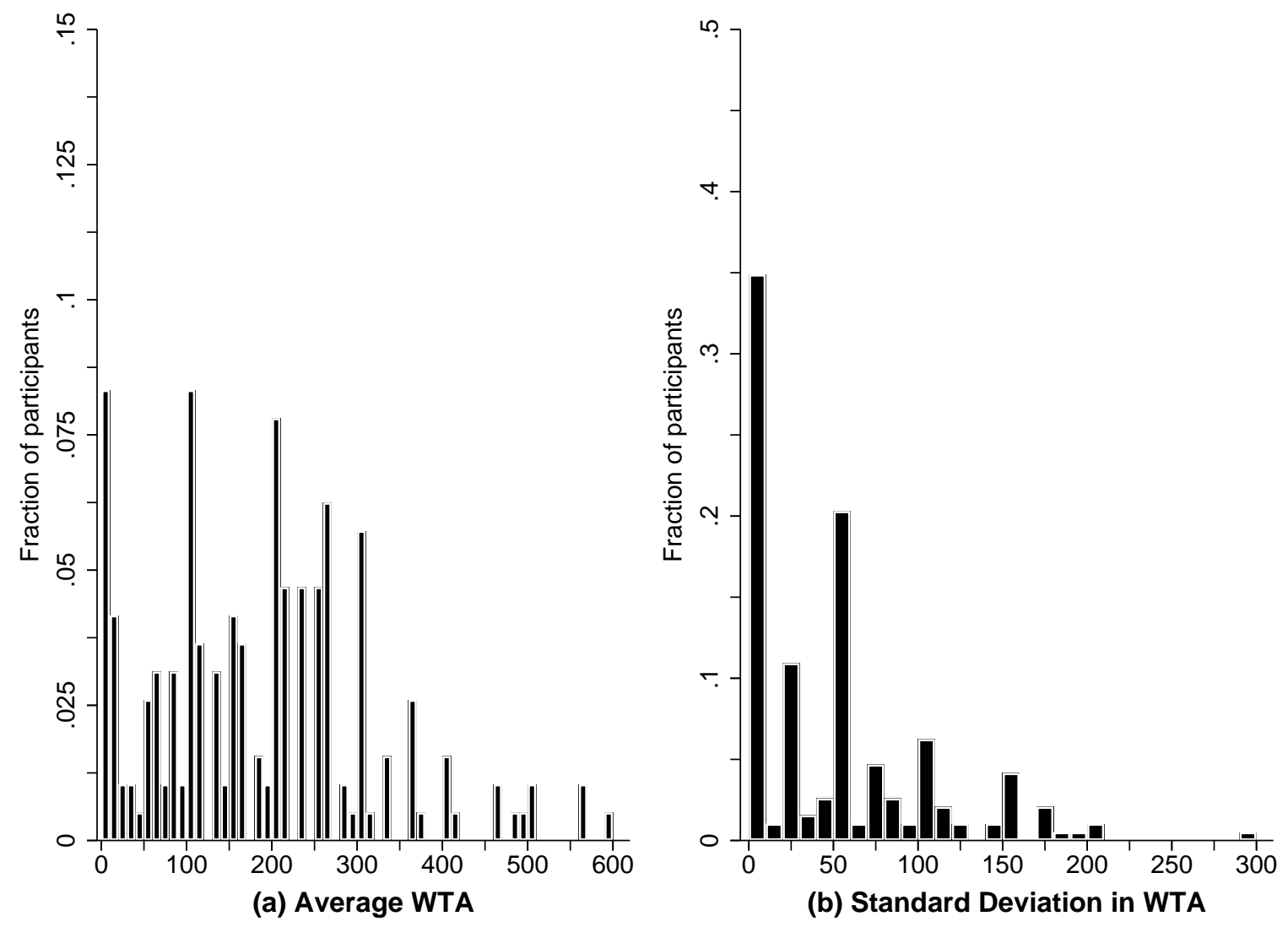

Figure B.2: WTA: Average and Standard Deviation - Pilot Study

Notes: Panel (a) presents the histogram of participants' average WTA over the three outgroups, panel (b) shows the histogram of the within-participant $W T A$ standard deviation across outgroups. 


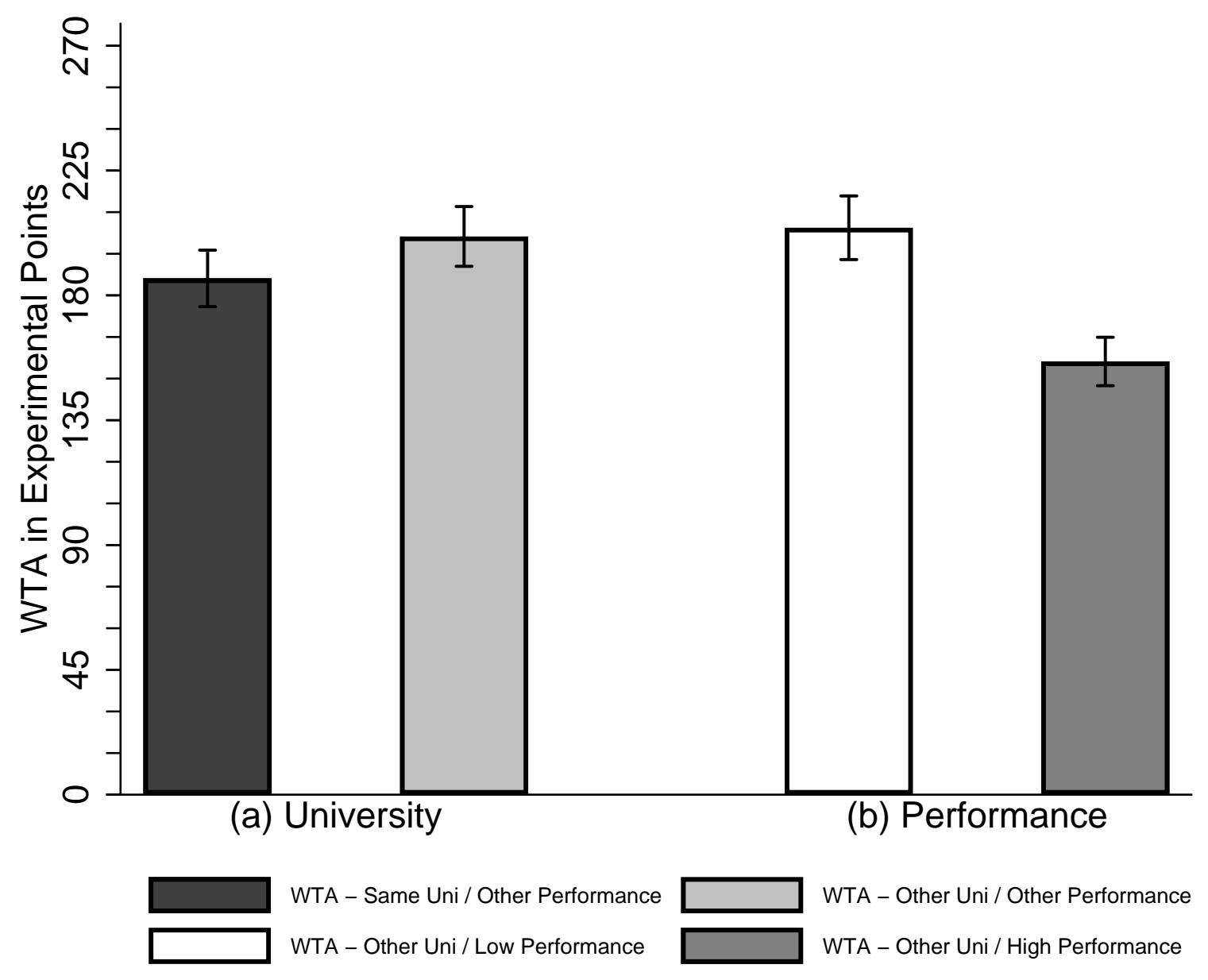

Figure B.3: Identification Preferences: Social Distance and Social Status - Pilot Study

Notes: The vertical axis indicates the $W T A$ in experimental points. The bars in panel (a) represent the social distance dimension (by varying outgroup university affiliation and holding outgroup performance constant) \pm SEs, the bars in panel (b) represent the social status dimension (by varying outgroup performance and holding outgroup university affiliation constant) \pm SEs. 

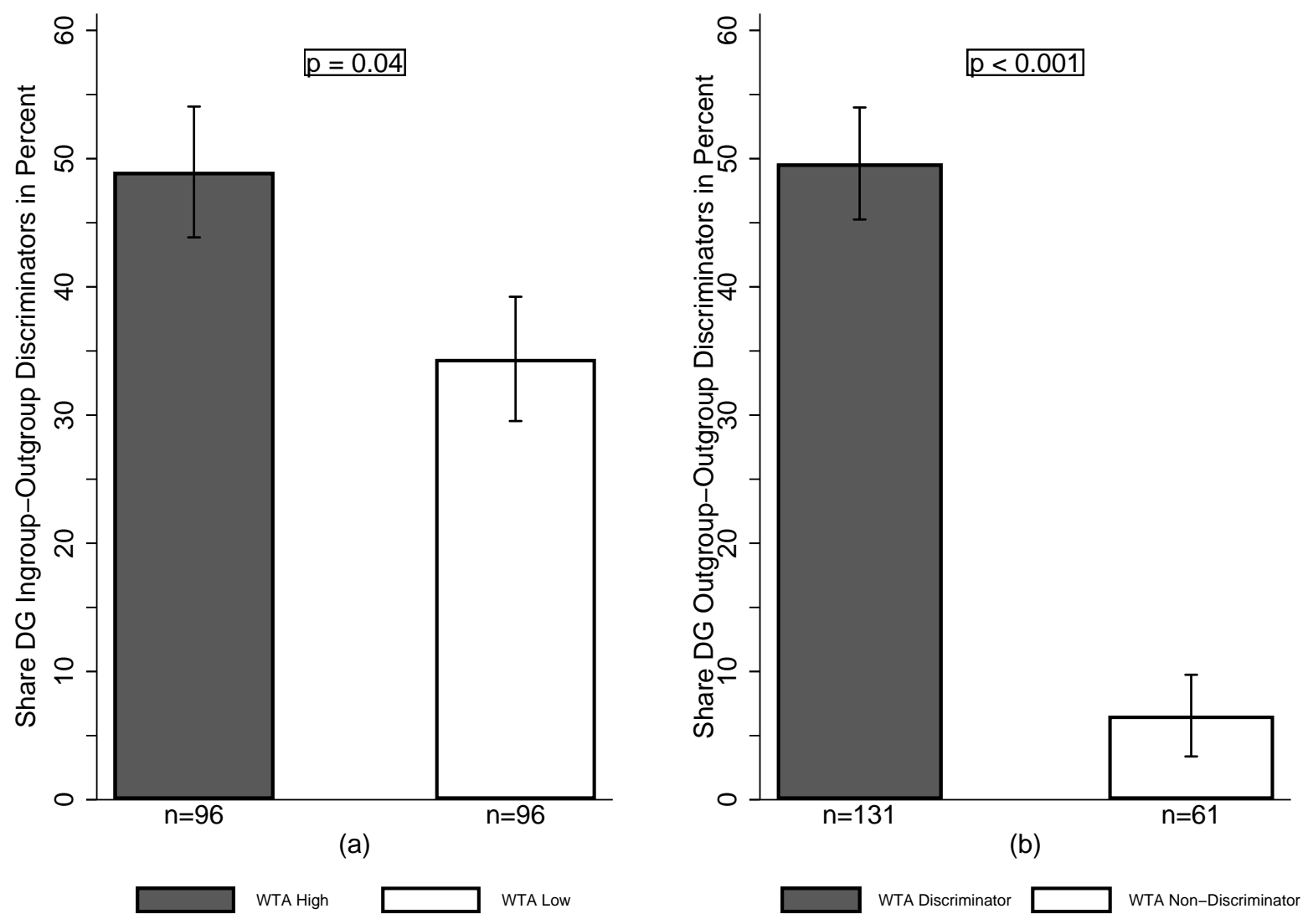

Figure B.4: Discrimination in Allocation Decisions: the Role of Identification Preferences - Pilot Study

Notes: In Panel (a), the vertical axis indicates the share of participants who discriminate between the own group and any of the three outgroups in at least one of the four dictator games. The sample is split by participants' average $W T A$ (grey bar: above median, white bar: below median). In Panel (b), the vertical axis indicates the share of participants who discriminate across the three outgroups in at least one of the four dictator games. The grey bar represents the participants who discriminate between outgroups with respect to their $W T A$, while the white bar represents those whose $W T A$ does not differ between outgroups. All bars \pm SE. $p$-values from two-sided Fisher's exact tests. 


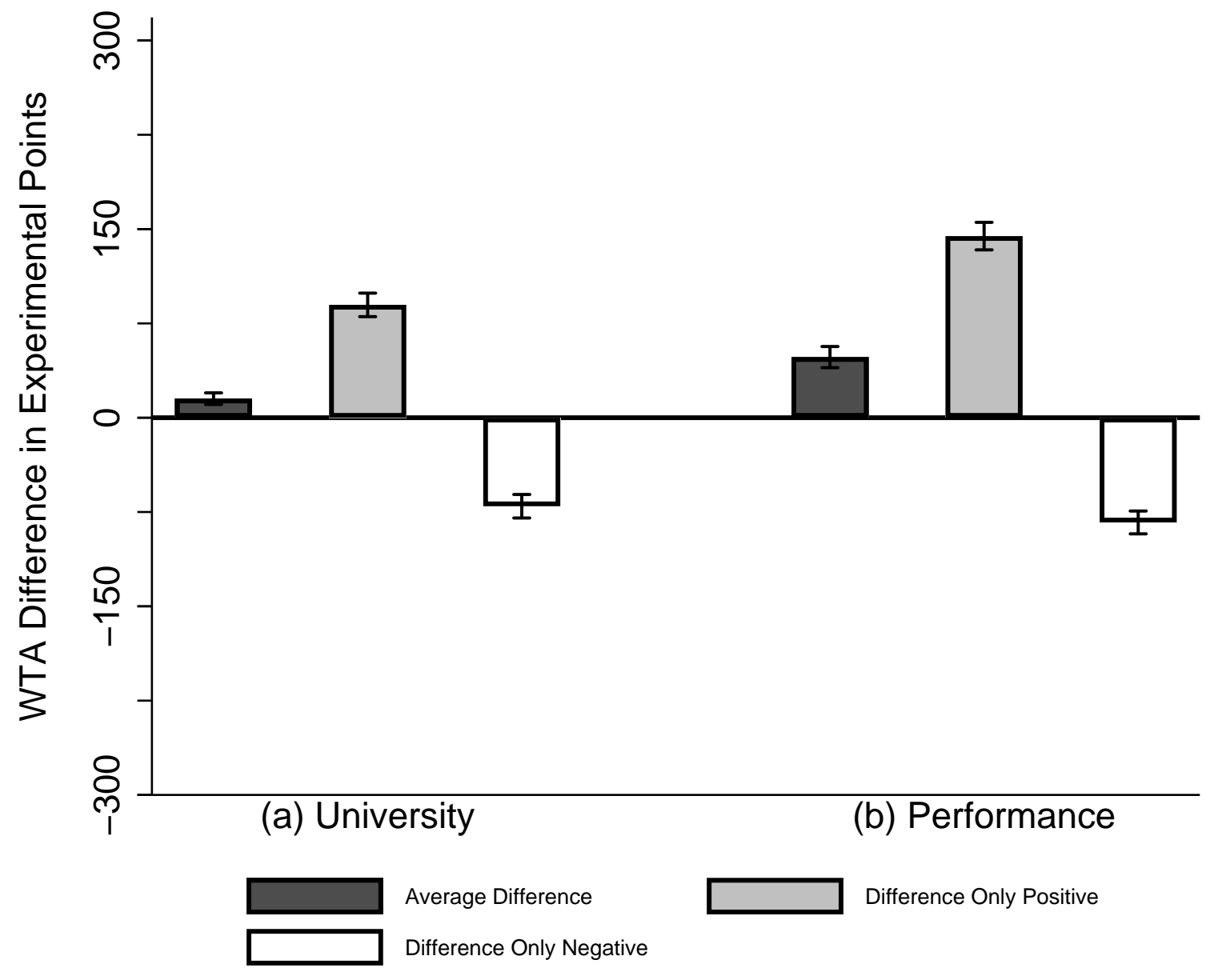

Figure B.5: Identification Preferences: Heterogeneity - Pilot Study

Notes: The vertical axis indicates the WTA difference in experimental points in (a) the university dimension and (b) the performance dimension. The light grey (white) bars show the averages for the subsamples of participants with positive (negative) WTA differences \pm SE. The dark grey bars refer to the full sample \pm SE. 


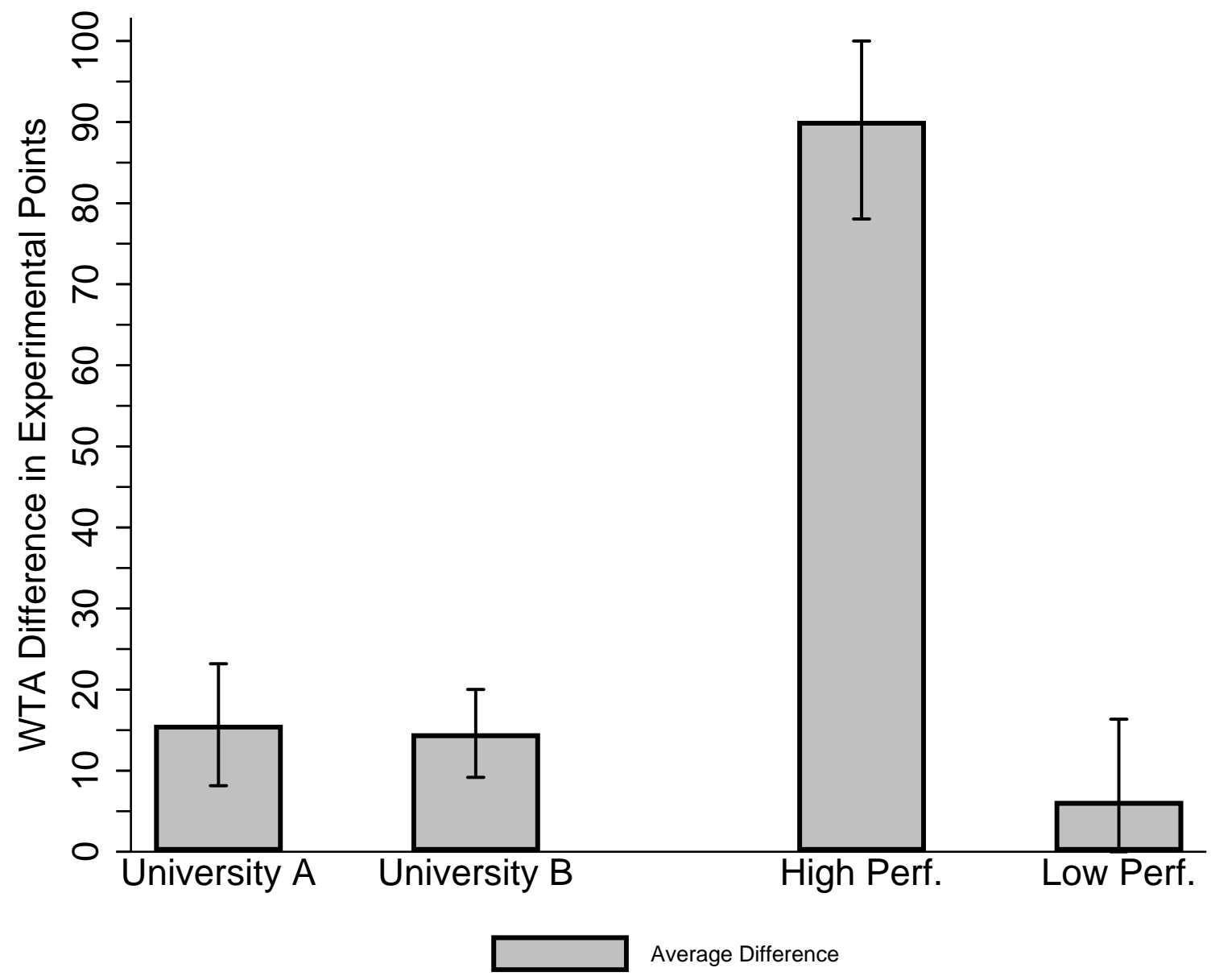

Figure B.6: Identification Preferences: Heterogeneity in Social Distance and Social Status - Pilot Study

Notes: The vertical axis indicates the $W T A$ difference in experimental points. Samples are split by universities (first two bars) and by math performance (bars three and four). The first two bars represent $W T A^{D i s t a n c e} \pm \mathrm{SEs}$ for the two university subsamples, while the last two bars report $W T A^{\text {Status }} \pm \mathrm{SEs}$ for the high and low performance groups. 


\section{Appendix C. Experimental Instructions (translated from German)}

\section{General Instructions - Printed on Paper}

Thank you for your participation in this scientific study. Please read through the instructions carefully. Everything that you have to know about the participation in this study will be explained in the following. If you have any difficulties in understanding the instructions, please raise your hand. We will then come to your place and answer your question.

For your appearance on time to participate in this study, you receive 4 Euro. Throughout the experiment, you can earn additional money. Your earnings depend on your own decisions and those of the other participants. You have to make your decisions on the screen.

This study takes place simultaneously at the universities of Frankfurt and Cologne. The group of participants consists of football fans of the two clubs 1. FC Köln (in the Cologne lab) and Eintracht Frankfurt (in the Frankfurt lab).

Please note that, during the study, communication among participants is only allowed in the prepared chat windows. All other form of communication is prohibited. We request you to only use the open programs for the experiment. Communication with other participants as well as other cases of interference will lead to your exclusion from the experiment.

Note that all the information you provide will be treated confidentially and will not be given to third parties. The data only serves scientific purpose.

Please do now click the 'Continue'-button and follow the instructions.

\section{Instructions Stage I - Printed on Paper}

In the beginning you are asked to do some calculations. In each exercise, you have to add up three double-digit numbers.

Only when you solve the exercise correctly, the next exercise will appear.

You now have 90 seconds to solve as many exercises as you can.

\section{Instructions Stage II - Printed on Paper}

Within both laboratories, all participants are now assigned to four-person-groups, that is either a green group or an orange group. 
The selection into the groups depends on the number of exercises you have previously solved correctly. The twelve best performing participants of each laboratory will be allocated to one of the green groups whereas the twelve worst performing participants will be allocated to one of the orange groups.

So there are three green groups and three orange groups in each laboratory and the green group members have answered more questions correctly than the orange group members in round 1 . Neither you nor the other members of your group know each other's identity.

Following group assignment, you are asked to solve three picture puzzles, one after the other, such as the following. Each picture puzzle consists of four pictures that all have one main theme in common. In the given example, this main theme would be 'geometry' (picture top left: geometric shapes; picture top right: set square and compass; bottom left: geometric functions; bottom right: theorem of Pythagoras).

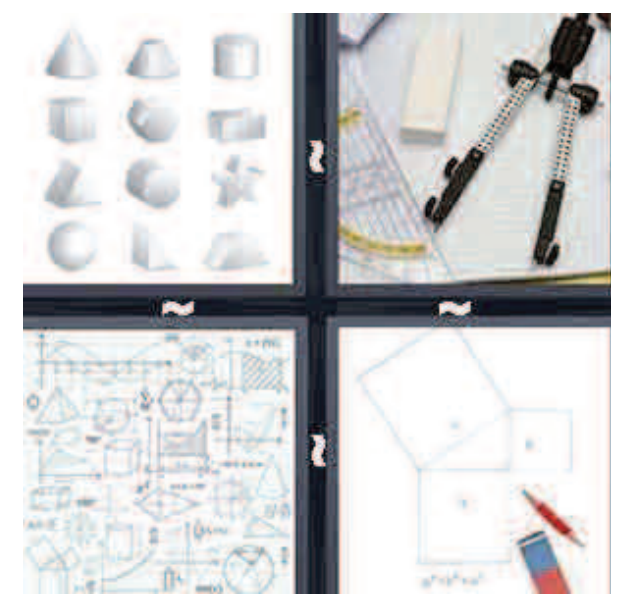

For each picture puzzle, you have 60 seconds to discuss with the other members of your group via the chat window. The chat messages sent by you are only visible for the members of your group. You can only see the messages sent by your own group members. After the one minute of discussion time you have 15 seconds to state your personal answer.

You will not be paid for a correct answer.

Note that you are allowed to exchange any content you want via the chat. However, it is prohibited to give any hints about your own identity via the chat. Doing so will lead to your exclusion from the experiment.

Do you have any remaining questions? If not, please click the 'Continue'-button to see which group you belong to. 


\section{Instructions Stage III (for Eintracht Frankfurt - High Performance) - Printed on Paper}

In the subsequent course of the experiment, there are four groups that are relevant for you. Your own green group of Eintracht Frankfurt supporters, one randomly chosen orange group of Eintracht Frankfurt supporters, and a randomly chosen green and a randomly chosen orange group of 1. FC Köln supporters.

One (and only one) participant from these four groups will now be randomly chosen. This participant will have the chance to be re-assigned to one of the three other groups. All remaining participants will stick with their initial groups.

In the next stage of the experiment, these four groups will be given random group-specific payoffs that range between $€ 0$ and $€ 8$. These payoffs are independent from stages I and II of this experiment. At the end of the experiment, every group member will receive the payoff that is given to her or his group. The participant who is eligible for re-assignment to another group will receive the payoff of the new group if she/he moves to the other group.

If you are chosen for re-assignment, you will have to decide whether you accept moving to another group or not. You will make your decision as follows:

You state the payoff differential between your own group and the other group (see the figure below) that is just big enough to make you accepting re-assignment to the other group. This will have the following consequences:

Case 1: The payoff differential between your green group of Eintracht Frankfurt supporters and the randomly drawn alternative group is larger than the payoff differential for which you would be willing to accept re-assignment to the alternative group. Hence you will change groups: You will then receive the payoff of the other group and will be part of the other group for the remainder of the experiment.

Case 2: The payoff differential between your green group of Eintracht Frankfurt supporters and the randomly drawn alternative group is smaller than the payoff differential for which you would be willing to accept re-assignment to the alternative group. Hence you will not change groups: You will then receive the payoff of your own green Eintracht Frankfurt group and will stay in your initial group for the remainder of the experiment.

You will make your decisions with the help of three sliders - one for each of the other groups - and have the following options (see the figure above):

- A positive payoff differential implies that you accept re-assignment to another group only if 


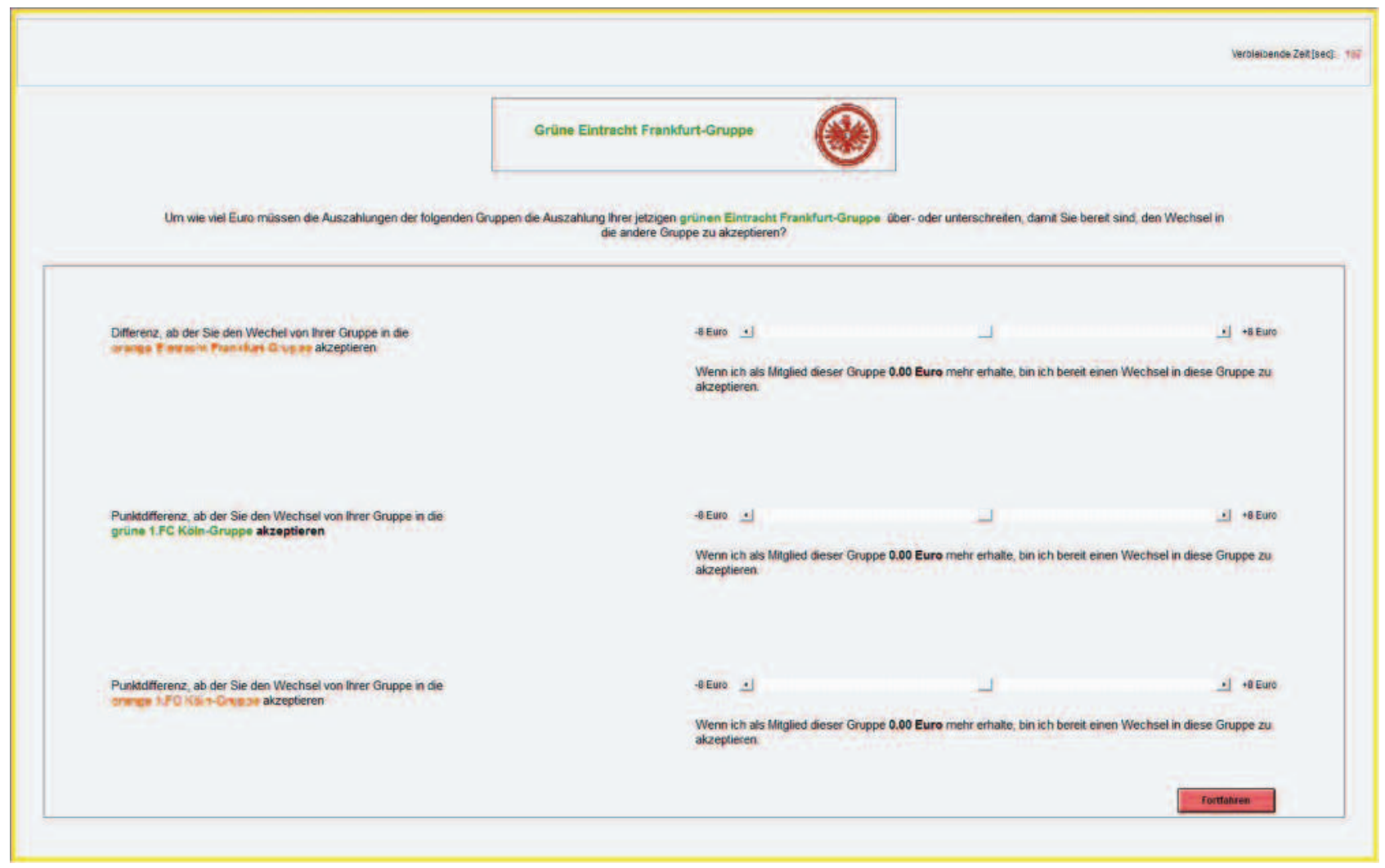

this group's payoff exceeds your own group's payoff by at least the stated differential.

- A negative payoff differential implies that you accept re-assignment to another group even if this group's payoff is lower than your own group's payoff (as long as the differential is smaller than the stated differential).

- A payoff differential of 0 implies that you accept re-assignment to another group whenever this group's payoff is larger than or the same as your own group's payoff.

In the following, there are three more examples for illustration:

Example 1: You have been randomly selected for re-assignment to the orange Eintracht Frankfurt group. Your stated minimal payoff differential implies that you accept re-assignment if the payoff of the orange Eintracht Frankfurt group is at least $€ 2.10$ higher than your own group's payoff. The randomly drawn payoff for each member of the orange Eintracht Frankfurt group is $€ 6.70$, your own group's randomly determined payoff is $€ 4.90$. As the payoff differential of $€ 1.80$ ( $€ 6.70$ - $€ 4.90)$ is smaller than your minimal acceptable payoff differential of $€ 2.10$, you will not be reassigned. You stick with your initial group.

Example 2: You have been randomly selected for re-assignment to the green 1. FC Köln group. Your stated minimal payoff differential implies that you accept re-assignment if the payoff of the 
green 1. FC Köln group is at least $€ 1.00$ higher than your own group's payoff. The randomly drawn payoff for each member of the green 1. FC Köln group is $€ 7.20$, your own group's randomly determined payoff is $€ 4.20$. As the payoff differential of $€ 3.00$ ( $€ 7.20-€ 4.20)$ exceeds your minimal acceptable payoff differential of $€ 1.00$, you will be re-assigned to the green 1. FC Köln group.

Example 3: You have been randomly selected for re-assignment to the orange 1. FC Köln group. Your stated minimal payoff differential implies that you accept re-assignment if the payoff of the orange 1. FC Köln group is at maximum $€ 1.50$ lower than your own group's payoff. The randomly drawn payoff for each member of the orange 1. FC Köln group is $€ 6.50$, your own group's randomly determined payoff is $€ 8.00$. As the payoff differential of $-€ 1.50$ (€6.50- $€ 8.00)$ exactly matches

your minimal acceptable payoff difference of $-€ 1.50$, you will be re-assigned to the orange 1 . FC Köln group.

Do you have any remaining questions? If not, please click the 'Continue'-button to see which group you belong to.

\section{Control Questions - On-screen}

Please answer the following control questions.

1. Assume that a participant wants to leave her/his group under no circumstance. Which strategy should she/he choose?

1. She/he should choose a minimal acceptable payoff differential of $€ 0$ for all three groups.

2. She/he should choose a minimal acceptable payoff differential of $€ 8$ for all three groups.

3. She/he should choose a minimal acceptable payoff differential of $-€ 8$ for all three groups.

4. She/he should choose varying minimal acceptable payoff differentials for the three groups.

2. Assume that a participant wants to definitely leave her/his group. Which strategy should she/he choose?

1. She/he should choose a minimal acceptable payoff differential of $€ 0$ for all three groups.

2. She/he should choose a minimal acceptable payoff differential of $€ 8$ for all three groups.

3. She/he should choose a minimal acceptable payoff differential of $-€ 8$ for all three groups.

4. She/he should choose varying minimal acceptable payoff differentials for the three groups.

3. Assume that a participant wants to maximize her/his monetary payoff from the group choice. Which strategy should she/he choose?

1. She/he should choose a minimal acceptable payoff differential of $€ 0$ for all three groups. 
2. She/he should choose a minimal acceptable payoff differential of $€ 8$ for all three groups.

3. She/he should choose a minimal acceptable payoff differential of $-€ 8$ for all three groups.

4. She/he should choose varying minimal acceptable payoff differentials for the three groups.

4. Assume that a participant would accept re-assignment to group A rather than re-assignment to groups B and C. Which strategy should she/he choose?

1. She/he should choose a higher minimal acceptable payoff differential for group A than for groups B and C.

2. She/he should choose a lower minimal acceptable payoff differential for group A than for groups B and C.

3. She/he should choose the same minimal acceptable payoff differential for groups A, B, and C.

\section{Stage III Information - On-screen}

On the next screen, you can state your minimal acceptable payoff differentials between your group and each of the three other groups.

After this experimental stage, you will take another series of individual choices which are independent of your group assignment. Only after these decisions, you and all other participants will be informed about the randomly drawn group payoffs, which of the 16 participants has been drawn for group re-assignment, and whether this participant accepted re-assignment or not.

In the subsequent stage, there will be three additional picture puzzles which will be solved in the potentially newly composed groups (if one player was re-assigned to another group). These picture puzzles will follow exactly the same rules as in the previous round. For each picture puzzle, you have 60 seconds to discuss with the other members of your group via the chat window. The chat messages sent by you are only visible for the members of your group. You can only see the messages sent by your own group members. After the one minute of discussion time you have 15 seconds to state your personal answer. The only difference to the previous round of picture puzzles is that the composition of two groups might differ if one participant was re-assigned to a new group.

As in the previous round, you will not be paid for a correct answer.

\section{Instructions Stage IV (for Eintracht Frankfurt - High Performance) - Printed on Paper}

In the fourth stage of the experiment, you will be randomly matched with another anonymous participant. The other participant can be a member of your initial green Eintracht Frankfurt group 
or any of the other three groups assigned at the beginning of the experiment.

Player 1 receives $€ 10$, player 2 receives $€ 5$.

If you are player 1 , your options are as follows:

1. You can send money to player 2. For every Euro of your endowment of $€ 10$ which you send to player 2, player 2 will receive 2 Euros.

2. You can take away money from player 2. For every Euro of player 2's endowment of $€ 5$ which you take away, you will receive 50 Cents.

3. You can keep your endowment without taking away money from player 2 .

You can implement your decisions with the help of a slider in steps of 10 Cents. This is, you can send up to $€ 10$ to player 2 or you can take away up to $€ 5$ from player 2 .

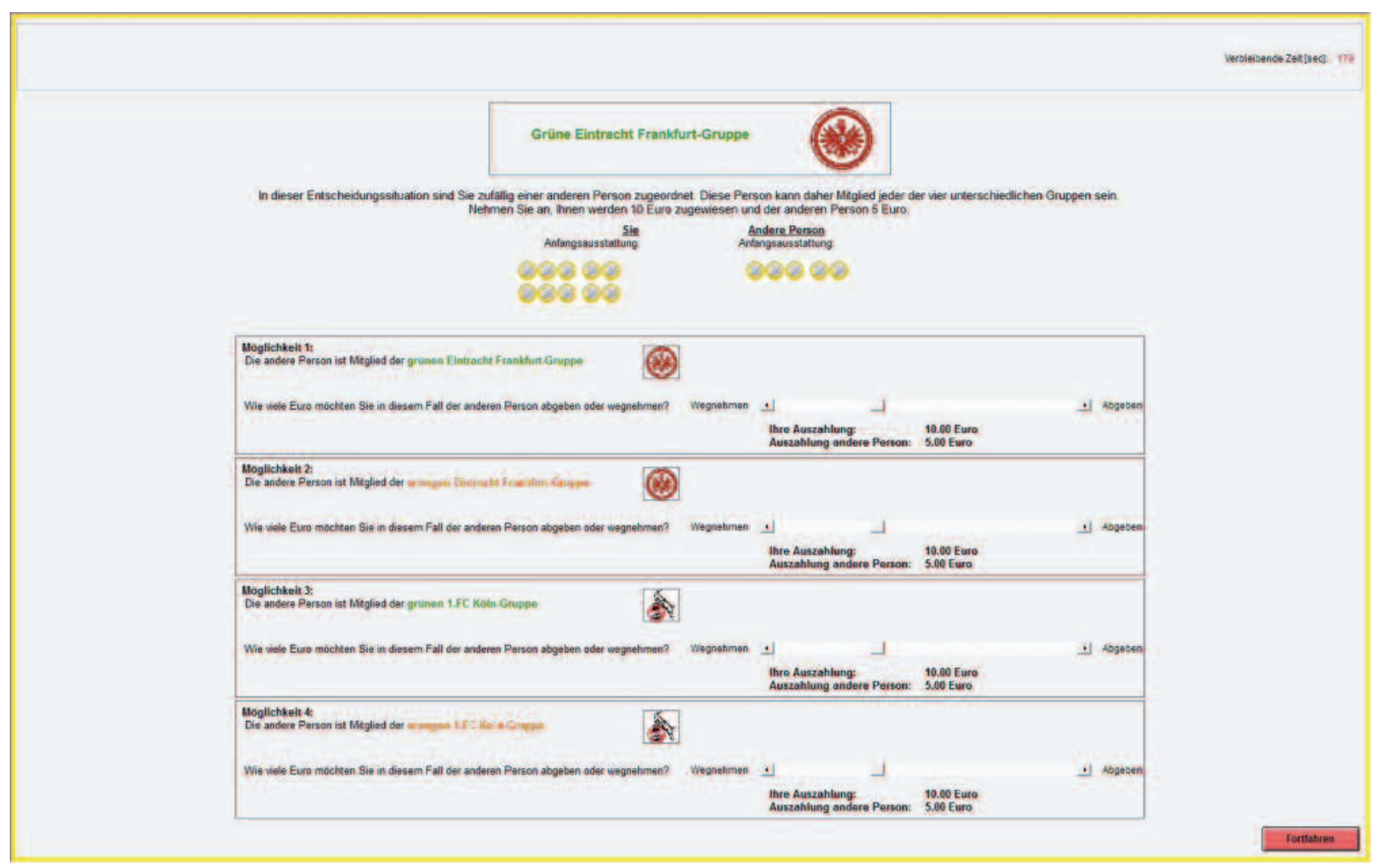

Both you and the other player take the player 1 decisions independently for four different scenarios:

- Player 2 is member of your own green Eintracht Frankfurt group.

- Player 2 is member of the orange Eintracht Frankfurt group.

- Player 2 is member of the green 1. FC Köln group. 
- Player 2 is member of the orange 1. FC Köln group.

At the end of the experiment, one scenario (and your according player 1 or 2 role) will be chosen randomly to determine your payoff. All games and both of the two roles A and B have the same probability of being chosen.

Do you have any remaining questions? If not, please click the 'Continue'-button and answer the control questions.

\section{Instructions Stage V - On-screen}

Please do now solve the following three picture puzzles. You again have 60 seconds to advise with your green Eintracht Frankfurt group before you give your answer. 